\title{
Structure of the Semiquinone Form of Flavodoxin from Clostridium MP
}

\section{Extension of $1.8 \AA$ Resolution and Some Comparisons with the Oxidized State}

\author{
Ward W. Smith, Roger M. Burnett $†$, George D. Darling $\ddagger$ \\ and Martha L. Ludwig; \\ Biophysics Research Division and Department of Biological Chemistry \\ University of Michigan, Ann Arbor, Mich. 48109, U.S.A.
}

(Received 20 April 1977, and in revised form 20 July 1977)

As part of a series of comparisons of the structures of the three oxidation states of flavodoxin from Clostridium $M P$, phases for the semiquinone form were determined to $2 \cdot 0 \AA$ resolution by isomorphous replacement $(<m>=0.725)$. Subsequently, the structure was refined at $1.8 \AA$ resolution by a combination of difference Fourier, real space and reciprocal space methods. After refining to an $R$ of $0 \cdot 194$, we explored the conformation of the FMN binding site by real space refinement versus maps with Fourier coefficients of the form $\left(2\left|F_{\mathrm{o}}\right|-\left|F_{\mathrm{c}}\right|\right) \exp$ $\left(i \alpha_{c}\right)$. To minimize bias in the fitting, groups of atoms were systematically omitted from the structure factors used in computation of the $\left(2\left|F_{\mathrm{o}}\right|-\left|F_{\mathrm{c}}\right|\right)$ maps.

One-electron reduction of oxidized flavodoxin is accompanied by several changes at the FMN binding site: the conformation of residues in the reverse bend formed by Met56-Gly57-Asp58-Glu59 differs in the crystal structures of the oxidized and semiquinone species; further, backbone atoms in residues 55 and 89 shift by more than $0.5 \AA$ and the indole ring of Trp90 undergoes a significant displacement. The orientation of the peptide unit connecting Gly57 and Asp58 is consistent with the presence of a hydrogen bond between the carbonyl oxygen of Gly57 and the flavin $\mathrm{N}(5)$ in flavodoxin semiquinone. No equivalent bond is found in oxidized flavodoxin. In both the oxidized and semiquinone species of clostridial flavodoxin, the isoalloxazine ring is essentially planar: the bending angles about $\mathrm{N}(5)-\mathrm{N}(10)$ are $\sim 2 \cdot 5^{\circ}$ for the semiquinone structure and $\sim 0^{\circ}$ in oxidized flavodoxin.

The intensity changes resulting from the oxidized $\rightleftharpoons$ semiquinone conversion $\left(R_{\mathrm{I}}=0 \cdot 33\right)$ arise in part from changes in molecular packing. Intermolecular contacts, including neighbors of the prosthetic group, are altered in the repacking. Maps or models of the two oxidation states can be brought into approximate coincidence by a rigid body motion. The required transformation, determined for the isomorphous replacement maps by the method of Cox (1967), is equivalent to a screw motion with a rotation of $1 \cdot 18^{\circ}$ and a translation of $-0 \cdot 34 \AA$. The molecular structures of oxidized and semiquinone flavodoxins have been com. pared after superposition of models with idealized co-ordinates and discrepancy indices $R_{\mathrm{ox}}=0 \cdot 213$ and $R_{\mathrm{sq}}=0 \cdot 200$. The root-mean-square distance between 523 backbone atoms (excluding sequences 50 to 59 and 89 to 91 ) is $0.308 \mathrm{~A}$.

$\dagger$ Present address: Department of Structural Biology, Biozentrum der Universitat Basel, Basel, Switzerland.

¥ Present address: Biology Department, Brookhaven National Laboratory, Upton, N.Y. 11973, U.S.A. 


\section{Introduction}

Flavodoxins are a group of flavoprotein electron carriers which can substitute for ferredoxins in many ferredoxin-dependent reactions (Smillie, 1965; Knight \& Hardy, 1966; Mayhew \& Ludwig, 1975). The two one-electron oxidation-reduction potentials of bound flavin mononucleotide are sufficiently different in the flavodoxins to permit characterization of each of the three oxidation states (Mayhew, 1971a; van Lin \& Bothe, 1972). Crystal structures have been determined for flavodoxins from two species, Desulfovibrio vulgaris (Watenpaugh et al., 1972,1973a) and Clostridium MP (Andersen et al., 1972). The oxidized states have been most thoroughly described (Watenpaugh et al., 1972,1973 a Burnett et al., 1974); the structure of the semiquinone, or radical, form of Clostridium $M P$ flavodoxin has been reported at $3 \cdot 25 \AA$ resolution (Andersen et al., 1972) and some further descriptions of the semiquinone and reduced states have appeared in brief preliminary accounts (Ludwig et al., 1975; Ludwig et al.. 1976; Watenpaugh et al., 1976).

Flavodoxin electron carriers characteristically display oxidation-reduction potentials near those of the ferredoxins, about $-0.4 \mathrm{~V}$, for the semiquinone/fully reduced equilibrium (van Lin \& Bothe, 1972; Mayhew \& Ludwig, 1975). The potentials are unusually low for flavins and may be crucial for the functional interchangeability of ferredoxins and flavodoxins (Mayhew et al., 1969). In many flavodoxins, the other redox potential, for the oxidized/semiquinone couple, also deviates considerably from the value of $-0 \cdot 24 \mathrm{~V}(\mathrm{pH} 7)$ determined for free FMN (Draper \& Ingraham, 1968). Perturbation of the FMN potential requires that the $K_{e a}$ for association of the apoprotein with FMN vary with oxidation state of the prosthetic group. From the potentials of $-0.092 \mathrm{~V}$ and $0.399 \mathrm{~V}(\mathrm{pH} 7)$ measured by Mayhew $(1971 a, b)$ for flavodoxin from Clostridium $M P, K_{\text {ox }} / K_{\text {sq }}$ must equal $\sim 10^{-2}$ and $K_{\text {sq }} / K_{\text {red }}$ must be $\sim 10^{4}$. We anticipated that these variations in the free energy of binding might be correlated with distinctive features of the three-dimensional structures of the several oxidation states.

Elucidation of the differences between crystal structures of the oxidized and semiquinone (radical) forms of clostridial flavodoxin has been complicated by nonisomorphism. Although both oxidation states crystallize in the same space group, $P 3_{1} 21$, the $c$ axis increases from $70 \cdot 36 \AA$ in the oxidized state to $70.98 \AA$ in the semiquinone form (Burnett et al., 1974; Andersen et al., 1972), and the discrepancy index for intensities, defined as

$$
R=\left(\sum\left|I_{\mathrm{ox}}-I_{\mathrm{sq}}\right|\right) /\left(\sum\left(I_{\mathrm{ox}}+I_{\mathrm{sq}}\right)\right),
$$

is $0 \cdot 33$ for all observable reflections to $2 \cdot 0 \AA$ resolution. We therefore elected to phase each structure independently. Fortunately the same binding sites for SmIII and AuI were accessible in both crystals.

This paper describes extension of the resolution of the semiquinone structure from $3.25 \AA$ to $2.0 \AA$ with the use of multiple isomorphous replacement phases. Including data to $1.8 \AA$, we have refined the structure by difference Fourier (Watenpaugh et $a l ., 1973 b$; Freer et $a l ., 1975$ ), real space (Diamond, 1971; Huher ot al., 1974), and reciprocal space (Hoard \& Nordman, unpublished data) methods to arrive at more accurate conformations for FMN and the residues in the flavin binding site. The active center of flavodoxin semiquinone is examined in detail and compared with the FMN binding site of oxidized flavodoxin. 


\section{Experimental and Methods}

(a) Crystallization and derivative preparation

Flavodoxin semiquinone crystallizes from ammonium sulfate in space group $P 3_{1} 21$ (Ludwig et al., 1969; Burnett et al., 1974). The cell dimensions, determined on a diffractometer, are $a=61.63 \pm 0.04 \AA, c=70.98 \pm 0.05 \AA$. Crystallizations are conducted in a glove box under nitrogen at $4^{\circ} \mathrm{C}$ and $\mathrm{pH} 6.8$ after addition of slightly more than 1 equivalent of dithionite to solutions of oxidized flavodoxin. At half reduction, the fraction of the semiquinone form approaches 1.0 (Mayhew, 1971a). Furthermore, the kinetics of the oxidation reactions favor maintenance of the intermediate oxidation state. Under the conditions used for erystallization, reoxidation of the semiquinone is exceedingly slow whereas fully reduced flavodoxin oxidizes relatively readily. Crystals of the semiquinone and oxidized forms can be distinguished by their unit cell dimensions and diffracted intensities, but semiquinone and fully reduced crystals are nearly isomorphous (Ludwig et al., 1971). By electron paramagnetic resonance measurements, the content of flavin radical has been shown to be greater than $95 \%$ in crystals prepared as described (Andersen, 1972 ), and visible spectra of crystals indicate that the semiquinone form predominates after cautious addition of dithionite (Eaton et al., 1975).

Heavy-atom derivatives were also prepared in the nitrogen-filled glove box, by soaking crystals in $0.020 \mathrm{M}-\mathrm{SmCl}_{3}$ or dialyzing versus $0.020 \mathrm{M}-\mathrm{Au}(\mathrm{CN})_{2}^{-}$. using the same conditions as for oxidized flavodoxin (Burnett et al., 1974).

\section{(b) X-ray measurements}

X-ray intensities were measured with a Syntex $P \bar{I}$ diffractometer equipped with a graphite monochromator, using the procedures of Burnett et al. (1974). Peak scans of $0.14^{\circ}$ were divided into steps of $0.02^{\circ}$ in $\omega$ and intensities determined according to Wyckoff et al. (1967); backgrounds were measured for each reflection at resolutions less than $3 \AA$ and were taken from a smoothed curve as a function of $2 \theta$ beyond $3 \AA$. Absorption corrections were determined empirically (North et al., 1968). Reflections whose intensities were very small for native crystals were not measured for the derivatives, reducing the number of unique reflections to $2.0 \AA$ from approx. 11040 to 8275 . The omitted reflections contributed about $6 \%$ of the total structure factor amplitudes.

The number of reflections which could be measured using one crystal was limited more by oxidation than by radiation damage. The extent of oxidation was estimated from both the change in the $c$ axis, which decreases from $70.98 \AA$ in the semiquinone to $70.36 \AA$ in oxidized crystals, and from the intensities of a set of check reflections known to be sensitive to oxidation state. Data collection was terminated when the changes indicated $15 \%$ oxidation.

Five crystals comprise the native data set to $2.0 \AA$; scaling of intensities from these crystals (Rue, 1965) resulted in values of $R_{\mathrm{I}}=\left(\sum\left|I_{\mathrm{i}}-I_{\mathrm{j}}\right|\right) /\left(\sum\left(I_{\mathrm{i}}+I_{\mathrm{j}}\right)\right.$ from 0.0324 to 0.0651 .1142 overlapping measurements at resolutions less than $2.0 \AA$ were used to place data from 2.0 to $1.8 \AA$ on the same relative scale as the $2.0 \AA$ set; $R_{\text {I }}$ was 0.0683 . For the 3 samarium erystals, $R_{\mathrm{I}}$ was 0.0734 to 0.0845 , and for tho 2 gold erystals, $R_{\mathrm{I}}=0.0653$.

\section{(c) Isomorphous replacement phasing}

Heavy-atom refinement and phase determination followed standard procedures (Lipscomb et al., 1966; Muirhead et al., 1967; Dickerson et al., 1968). Anomalous scattering differences from both gold and samarium derivatives were incorporated in the computation of phase probability profiles (North, 1965; Wyckoff et al., 1970). $\Delta F^{ \pm}$was calculated

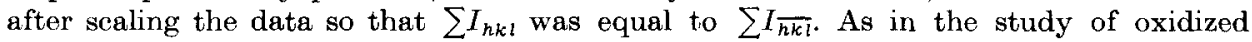
flavodoxin (Burnett et al., 1974), heavy atoms were initially refined using centric reflections and unit weights. Possible minor sites detected in residual maps (Matthews, 1970) were tested by refinement of the occupancy. Parameters from the centric refinement provided starting values for 11 cycles of alternate phasing and heavy-atom refinement with 3 -dimensional data (8234 reflections with $|F|$ greater than 40 (scale of Table 2)). The mean change in phase angle in the last cycle was $1.03^{\circ}$. Table 2 lists the parameters used in the final cycle of phasing, and Fig. 1 gives some statistical measures of the results. 


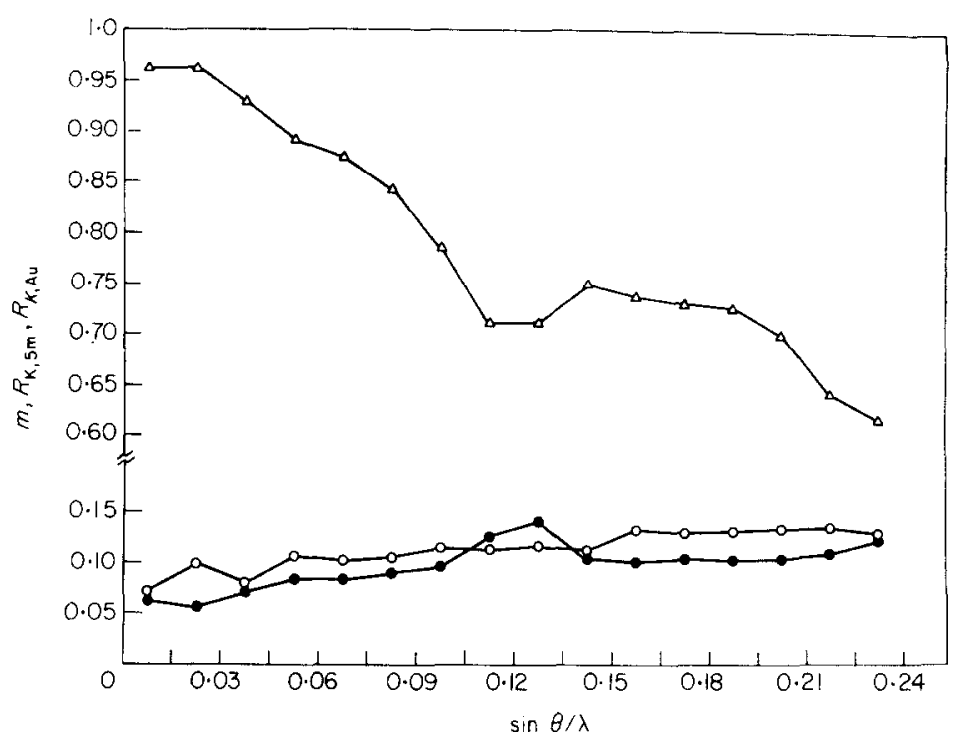

Fra. 1. Results of heavy-atom refinement and isomorphous replacement phase determination. The figure of merit and the values of $R_{\mathrm{K}}$ (Kraut et al., 1964) are plotted as a function of $\sin \theta / \lambda$. $-\triangle-\triangle-, m ;-\mathrm{O}-\mathrm{O}-, R_{\mathrm{K} . \mathrm{sm}} ;-\mathrm{O}-, R_{\mathrm{K}, \mathrm{Au}}$.

Estimates of heavy-atom occupancies, using centric data from individual derivative crystals, had suggested that the 3 samarium crystals be assigned the same heavy-atom parameters. The scaled data were therefore treated as 1 derivative. A similar procedure was followed for the gold crystals. However, the increased $R_{\mathrm{K}}$ (Fig. 1) in the region where data from the 2 gold crystals overlap may indicate some small differences in the heavyatom parameters for these individual data sets.

\section{(d) Refinement}

Refinement of the model structure of flavodoxin semiquinone is considered in detail elsowhere and is only summarized horo (Table 1). Quotations of $R$ factors refer only to those reflections for which $I>2 \sigma$ (Watenpaugh et al., 1973b). Ignoring the smallest reflections includes 11,141 of the total 14,862 reflections between $15 \AA$ and $1.8 \AA$, and 1463 of the total 3948 between 2.0 and $1.8 \AA$. Real space refinement (Diamond, 1971) of the model of oxidized flavodoxin versus the semiquinone electron density (phased by isomorphous replacement) was followed by 4 cycles of difference Fourier refinement. Co-ordinate shifts were computed with gradients obtained by interpolation of the difference density (Freer et al., 1975). Temperature factors, initially assigned "by hand", were adjusted automatically in the last 2 cycles. Structure factors were computed by the routine described by Burnett \& Nordman (1974). After the 4th cycle, 1030 of the 1104 atoms and 112 solvents were iricluded in the structure factors for flavodoxin semiquinone. Co-ordinates were then idealized with Diamond's model-building program (Diamond, 1966) and subjected to real space refinement versus a map computed with coefficients $\left(2\left|F_{\mathrm{o}}\right|-\left|F_{\mathrm{c}}\right|\right) \exp \left(i \alpha_{\mathrm{c}}\right) \dagger$ (phases from the final difference Fourier parumeters). Replacement of the high-resolution data led to an $R$ value of $0 \cdot 247$.

Subsequent refinement was achieved by a reciprocal space least-square method in which residuos or subrcgions of rosiduce woro troatod as rigid groups (Hoard \& Nordman, unpublished results); FMN was refined as a single rigid group of 31 atoms. This procedure proved effective in reducing $R$ after difference Fourier shifts had become small. It was

†These maps will be referred to by the shorthand notation $\left(2\left|F_{\mathrm{o}}\right|-\left|F_{\mathrm{c}}\right|\right)$. Similar notation is followed for other difference maps. 
particularly useful for adjustment of individual atom thermal parameters, and for determination of the occupancies and positions of solvents. The resulting conformations are non-ideal at the junctions of groups.

For imposition of nearly-standard geometry, the programs of Hermans \& McQueen (1974) or of Levitt (1974) woro found proforablo to Diamond's (1966) modol-building in the sense that they produced a smaller increase in $R$. The final $R$ values of Table 1 were calculated for co-ordinates idealized according to Levitt (1974). Standard deviations from nominal hond lengths were $\sim 0.01 \&$ for protein atoms. Atoms in the FMN binding site were further adjusted by real space refinement versus $\left(2\left|F_{\mathrm{o}}\right|-\left|F_{\mathrm{c}}\right|\right)$ maps (see Results). Except for FMN and the atoms of the binding site, co-ordinates deposited at the Protein Data Bank correspond to the idealized sets of Table 1. Atoms for which we still observe no convincing electron density are noted in the Data Bank listing.

\section{Table 1}

Refinement of flavodoxins

\begin{tabular}{|c|c|c|c|c|}
\hline & $\begin{array}{l}\text { Protein } \\
\text { atoms }\end{array}$ & Solvents & $\begin{array}{l}\text { Resolution } \\
(A)\end{array}$ & $R$ \\
\hline \multicolumn{5}{|l|}{ A. Stages in refinement of flavodoxin semiquinone } \\
\hline $\begin{array}{l}\text { 1. Initial model : atoms from oxidized flavodoxin } \\
\text { transformed by expression I }\end{array}$ & $883 \dagger$ & 0 & $2-5$ & $0 \cdot 403$ \\
\hline $\begin{array}{l}\text { 2. Atoms positioned in density after real space } \\
\text { refinement with isomorphous replacement map }\end{array}$ & 1003 & 0 & $1 \cdot 8-5 \cdot 0$ & $0 \cdot 364$ \\
\hline $\begin{array}{l}\text { 3. Model after } 4 \text { cycles of difference Fourier } \\
\text { refinement }\end{array}$ & 1030 & 112 & $1 \cdot 8-5 \cdot 0$ & $0 \cdot 250$ \\
\hline $\begin{array}{l}\text { 4. Atoms positioned by real space refinement with } \\
\left(2 F_{0}-F_{\mathrm{c}}\right) \text { map }\end{array}$ & 1032 & 112 & $1 \cdot 8-5 \cdot 0$ & $0 \cdot 268$ \\
\hline 5. New data from 1.8 to $2 \cdot 0 \AA$ & 1032 & 112 & $1 \cdot 8-5 \cdot 0$ & $0 \cdot 247$ \\
\hline $\begin{array}{l}\text { 6. Model after } 2 \text { cycles of group least-squares } \\
\text { refinement }\end{array}$ & 1037 & 118 & $1 \cdot 8-5 \cdot 0$ & $0 \cdot 194$ \\
\hline 7. Subsequent energy minimization & & & & $0 \cdot 200$ \\
\hline \multicolumn{5}{|l|}{ B. Summary of refinement of oxidized flavodoxin } \\
\hline 1. After reciprocal space refinement & 1063 & 88 & $5 \cdot 0-1 \cdot 9$ & $0 \cdot 211$ \\
\hline 2. Subsoquent onorgy minimization & & & & $0 \cdot 214$ \\
\hline
\end{tabular}

† Includes FMN, but not residues 56 to 59 and 89 to 91 .

The FMN model for real space and group refinement (Fig. 7) was constructed with a planar isoalloxazine moiety having bond lengths within $0.007 \AA$ of those given by Wang \& Fritchie (1973) for an ideal flavin. The ribityl side-chain bond distances and angles were selected from the literature as noted in the legend of Fig. 7. Initial values of the variable dihedral angles designated in Fig. 7 were determined from a partially refined co-ordinate set for oxidized flavodoxin (Darling, 1975). Flexion of the FMN ring about $\mathrm{N}(5)-\mathrm{N}(10)$ was introduced by treating atoms $\mathrm{N}(5), \mathrm{C}(5 \mathrm{a}), \mathrm{C}(6) \ldots \mathrm{C}(9 \mathrm{a})$ as a sidechain attashed to $N(10)$ by the $N(5)-N(10)$ virtual bond and allowing the $N(5)-N(10)$ dihedral angle to vary.

The accuracy of the atomic positions in the semiquinone model has been estimated in 2 ways. Assuming that the conformation of the polypeptide backbone ought to be identical in the oxidized and semiquinone structures, except for a few residues in the active center, we can obtain positional errors from the distances separating equivalent atoms in the 
2 structures, which have been determined independently. After appropriate superposition of the models (Rao \& Rossmunn, 1973; Rossmann \& Argos, 1975) the root-mean-square distance separating backbone atoms is $0.308 \AA$. Letting this value equal $\sqrt{ } 2(\sigma(r))$ yields an average positional error of $0.22 \AA$. Alternatively the formulae of Cox \& Cruickshank (1948) can be used. For the trigonal space group:

$$
o(z)=-\frac{4 \pi}{c V C}\left[\sum_{h k l} l^{2}\left(\Delta F^{\prime}\right)^{2}\right]^{\frac{1}{2}},
$$

where $c$ is the unit cell dimension and $V$ the cell volume; and $\sigma(x)$ or $\sigma(y)$ contain additional cross-terms. (The errors have been multiplied by 2 because nearly all the data are acentric.) Curvatures, $C$, wero ostimated from the electron densities of isolated atoms having typical temperature factors and were (in $\left.e \AA^{-5}\right): \mathrm{C},-2.01 ; \mathrm{N},-2.53 ; 0,-2.77$; $\mathrm{S},-7.50 ; \mathrm{P},-8.55$. With $\Delta F$ values for all $I>2 \sigma$ within the range of 10 to $1.8 \AA$, we obtained the following $\sigma(z): \mathrm{C}, 0.099 \AA: \mathrm{N}, 0.081 \AA ; 0,0.072 \AA ; \mathrm{S}, 0.026 \AA ; \mathrm{P}, 0.023 \AA$. Corresponding positional errors, $\sigma(r)$, taken as $\sqrt{ } 3(\sigma(z))$ are: $\mathrm{C}, 0 \cdot 17 \AA ; \mathrm{N}, 0 \cdot 14 \AA ; \mathrm{O}$, $0.13 \AA ; \mathrm{S}, 0.046 \AA ; \mathrm{P}, 0.036 \AA$. These variances are larger than the true ones to the extent that errors in temperature factors also contribute to $\Delta F$; but exclusion of the innermost data and the smallest reflections will tend to decrease the calculated values.

\section{(e) Difference maps}

We have relied on real space refinement versus $\left(2\left|F_{\mathrm{o}}\right|-\left|F_{\mathrm{c}}\right|\right)$ maps (Huber et al., 1974) for determination of the positions of atoms in the active center. These maps are convenient when the refinement eneompasses regions where atoms have been omitted from $\vec{F}_{\text {c }}$, because the densities in deletion regions are comparable to densities in the adjoining regions of the map. In both $\left(2\left|F_{\mathrm{o}}\right|-\left|F_{\mathrm{c}}\right|\right)$ and $\left(\left|F_{\mathrm{o}}\right|-\left|F_{\mathrm{c}}\right|\right)$ maps, terms with $I<\mathbf{2 \sigma}$ and with $\left|F_{\mathrm{c}}\right| /\left|F_{\mathrm{o}}\right|$ less than $0 \cdot 3$ wore omitted. Bccause some of the $\left(\left|F_{\mathrm{o}}\right|-\left|F_{\mathrm{c}}\right|\right)$ maps showed that omission of data inside $5 \AA$ affected the shape of the computed density, reflections between 5 and $15 \AA$ were included in difference maps unless otherwise noted. $\left|F_{\mathrm{o}}\right|$ in the inner regions had to be rescaled to account for the effects of disordered solvent. The "Babinet" method of Moews \& Kretsinger (1975), in which the scattering of disordered solvent is assumed to have a phase opposite to that of the known portion of the structure, was employed. For our data, the two parameters, $K^{\prime \prime}$ and $\Delta B$, found by leastsquares fitting of the expression $\left[\left|F_{\mathrm{o}}\right|-\left(\left|F_{\mathrm{c}}\right| / K\right)\left\{1-K^{\prime \prime} \exp \left(-\Delta B \sin ^{2} \theta / \lambda^{2}\right)\right\}\right]^{2}$ were 0.579 to 0.596 and 112 to $127 \AA^{2}$.

\section{(f) Other programs}

Comparisons of model co-ordinates were performed with a program coded by R. M. Burnett and conceptually similar to the routine of Rossmann \& Argos (1975). Fourier prngrams were provided by G. N. Reeke, and Ten Eyck (1973); for the latter FFT the $P 3_{1} 21$ symmetry was reduced to $P 1$. Map transformations employed the routine written by Cox (1967), and the stereo drawings were prepared with ORTEP or a program written by $\mathrm{B}$. Wishner.

\section{Results}

(a) The isomorphous replacement map of flavodoxin semiquinone and its interpretation

The binding sites for heavy atoms (Table 2) are in equivalent positions in oxidized and semiquinone forms. In neither structure is it possible for SmIII to be bound at all sites simultaneously (Burnett et al., 1974). From Table 2 the distance between Sm sites are : 1 to $2,1.22 \AA ; 1$ to $3,2.45 \AA$; and 2 to $3,1.65 \AA$. However, the relative occupancies of these sites near Glu123 and Aspl22 are different in the two structure determinations. In particular, the distribution of $\mathrm{Sm}$ scattering in the two principal either/or sites ( 1 and 2 ) is almost equal in Table 2 , whereas in oxidized flavodoxin, site 2 has nearly double the occupancy of site 1 . 
TABLE 2

Heavy-atom parameters

\begin{tabular}{|c|c|c|c|c|c|c|c|}
\hline Atom & Site & $Z \dagger$ & $x$ & $y$ & $z$ & $B\left(\AA^{2}\right)$ & $\Delta B \ddagger\left(\AA^{2}\right)$ \\
\hline $\mathrm{Sm}$ & $\begin{array}{l}1 \\
2 \\
3\end{array}$ & $\begin{array}{l}32 \cdot 9 \\
30 \cdot 7 \\
12 \cdot 7\end{array}$ & $\begin{array}{l}0 \cdot 352 \\
0 \cdot 343 \\
0 \cdot 332\end{array}$ & $\begin{array}{l}0.243 \\
0.236 \\
0.253\end{array}$ & $\begin{array}{l}0 \cdot 144 \\
0 \cdot 160 \\
0 \cdot 170\end{array}$ & $\begin{array}{l}18 \cdot 4 \\
13 \cdot 0 \\
42 \cdot 7\end{array}$ & 1.976 \\
\hline Au & $\begin{array}{l}1 \\
2\end{array}$ & $\begin{array}{r}67.8 \\
1.8\end{array}$ & $\begin{array}{l}0.568 \\
0.288\end{array}$ & $\begin{array}{l}0.974 \\
0.750\end{array}$ & $\begin{array}{l}0.106 \\
0.061\end{array}$ & $\begin{array}{l}28 \cdot 1 \\
17 \cdot 1\end{array}$ & -0.578 \\
\hline
\end{tabular}

$\dagger$ Absolute scaling is only approximate.

$\ddagger$ Temperature factor applied to derivative $\left|F_{0}\right| s$ to make the decrease with $\sin \theta / \lambda$ identical to that for native data.

The figure of merit decreases from 0.964 for the shell between 20.0 and $16.0 \AA$ to $0 \cdot 615$ for the outermost range of resolution $(2 \cdot 1$ to $2 \cdot 0 \AA)$, with the overall $\langle m\rangle$ for data from $20 \cdot 0$ to $2 \cdot 0 \AA$ being 0.725 (Fig. 1). A portion of the map computed with isomorphous replacement phases can be seen in Figure 2.

From earlier comparisons of the structure of oxidized flavodoxin with the semiquinone structure at $3.25 \AA$ resolution, and from the nuclear magnetic resonance spectra (James et al., 1973), we knew the molecular conformations must be very similar in both oxidation states, despite the considerable changes in X-ray intensities. We therefore assumed that co-ordinates for the oxidized molecule could be employed to interpret the electron density of the semiquinone species. However, optical superposition (Richards, 1968) of the oxidized model on the semiquinone electron density disclosed discrepancies throughout the molecule. To position the model, we adopted two strategies: application of a rigid-body transformation to the semiquinone electron density, and real space refinement of the oxidized co-ordinates versus the semiquinone map.

The relative orientation of the isomorphous replacement maps of oxidized and semiquinone flavodoxins was established according to Cox (1967). The residual, $\sum(\Delta \rho)^{2}$, decreased to $63 \%$ of its initial value. The transformation relating the two maps is:

$$
\begin{aligned}
& X_{\mathrm{sq}}^{*}=0.99983 X_{\mathrm{ox}}^{*}+0.00288 Y_{\mathrm{ox}}+0.01835 Z_{\mathrm{ox}}-0.2534 \\
& Y_{\mathrm{sq}}=-0.00315 X_{\mathrm{ox}}^{*}+0.99995 Y_{\mathrm{ox}}+0.00909 Z_{\mathrm{ox}}-0.3784 \\
& Z_{\mathrm{sq}}=-0.01833 X_{\mathrm{ox}}^{*}-0.00914 Y_{\mathrm{ox}}+0.99979 Z_{\mathrm{ox}}+0.8304
\end{aligned}
$$

where $X^{*}, Y$, and $Z$ are in $\AA$, parallel to $a^{*}, b, c$ and the origin for rotation is at $X^{*}=9.52 \AA, Y=-12.06 \AA, Z=0.00 \AA$. The Euler angles are $-8.92^{\circ},-1 \cdot 06^{\circ}$ and $9 \cdot 44^{\circ} \dagger$. Conversion to the equivalent screw operation yields an axis with direction cosines relative to $a^{*}, b$ and $c$ of $-0.4407,0.8862$ and -0.1432 , intersecting the $a^{*} c$ plane at $X^{*}=42 \cdot 41 \AA$ and $Z=22 \cdot 45 \AA$. The screw rotation is $1 \cdot 18^{\circ}$ with a translation of $-0 \cdot 34 \AA$.

Differences in the figure of merit and resolution precluded point-by-point subtraction of the transformed semiquinone density from the oxidized density as a means 


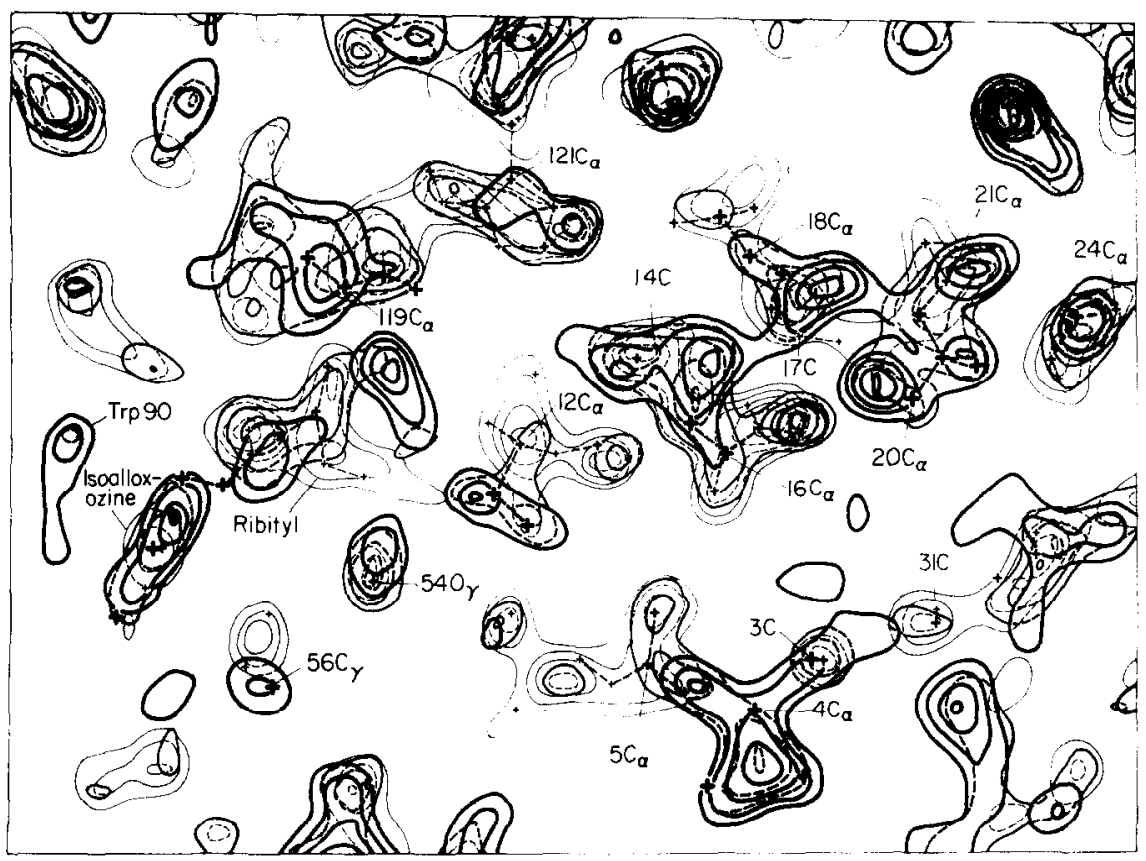

FIG. 2. A composite drawing of 3 sections $(z=0 \cdot 168,0 \cdot 179$ and $0 \cdot 190)$ through the electron density of flavodoxin semiquinone, computed with isomorphous replacement phases at a resolution of $2 \cdot 0 \AA$. A portion of the FMN is included, along with parts of 2 strands of the parallel sheet (residues 3 to 6 and 30 to 31) and a segment of $\alpha$ helix (residues 12 to 24). The atomic positions $(+)$ were transformed from the model of oxidized flavodoxin according to expression (I). Bonds lying in the sections shown are indicated by broken lines. Density corresponding to symmetryrelated molecules is not labeled.

of detecting possible conformational changes. Instead the transformed density was displayed in a Richards box (Richards, 1968) for visual comparison with the skeletal model of oxidized flavodoxin (Fig. 2). Density corresponding to residues 57 and 58, in a reverse bend adjacent to the FMN ring, had different shapes in the semiquinone and oxidized maps (Fig. 5). Small changes in the position of the Trp90 ring were also suggested. After further inspection of the map, we concluded that 883 atoms of the oxidized model could be placed in the transformed semiquinone density with confidence. The rigid-body transformation, see (I), above, reduced $R$ for these 883 atoms from $0 \cdot 445$ to $0 \cdot 403$ (Table 7 ).

Real space refinement, starting with the untransformed co-ordinates for oxidized flavodoxin, also produced a set of co-ordinates appropriate for the (untransformed) semiquinone structure, providing that the atom centers in the untransformed oxidized co-ordinate set resided in regions of sufficiently positive density in the semiquinone map. Revised co-ordinates were entered for atoms of the polypeptide backbone from $\mathrm{C}_{a} 56$ through $\mathrm{C}_{a} 59$. A cycle of real space refinement of the entire molecule was followed by a second cycle encompassing selected regions. Control parameters and other details of these calculations are given in Table 7 . After real space refinement, the $R$ factor for the same 883 atoms identified by visual inspection was $0 \cdot 397$. Further refinement proceeded from the co-ordinates derived by real space fitting of the isomorphous replacement map (Experimental and Methods). 


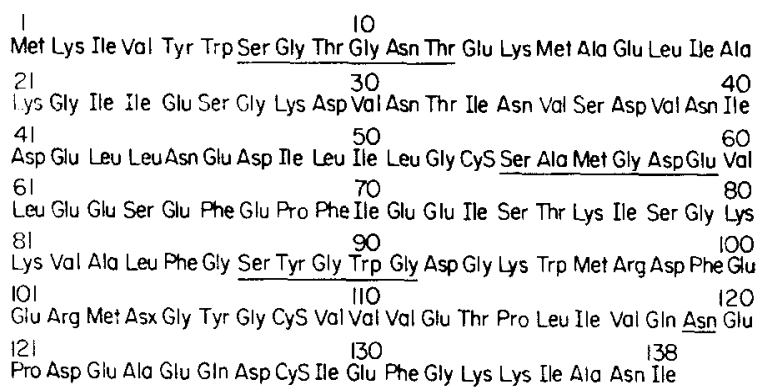

FIG. 3. The chemical sequence of flavodoxin from Clostridium MP, determined by Tanaka et al. (1974). Residues with atoms less than $4 \AA$ from FMN are underlined.

A stereo representation of the structure of flavodoxin semiquinone appears in Figure 4. As in oxidized flavodoxin (Burnett et al., 1974; Mayhew \& Ludwig, 1975) the polypeptide chain folds to form a parallel sheet flanked on either side by a pair of helices. The hydrogen-bonding scheme for the entire molecule will be presented elsewhere. The active center of flavodoxin semiquinone and some differences between the oxidized and semiquinone structures are considered in the following sections.

\section{(i) Background}

(b) The FMN binding site in flavodoxin semiquinone

Residues in sequences 7 to 12,54 to 59 and 87 to 91 , along with Asnl19, form the flavin binding site (Figs 4 and 8 ; Table 3). The flavin phosphate interacts primarily with residues 7 to 12 and the isoalloxazine ring with residues 56 to 59 and 89 to 91 .
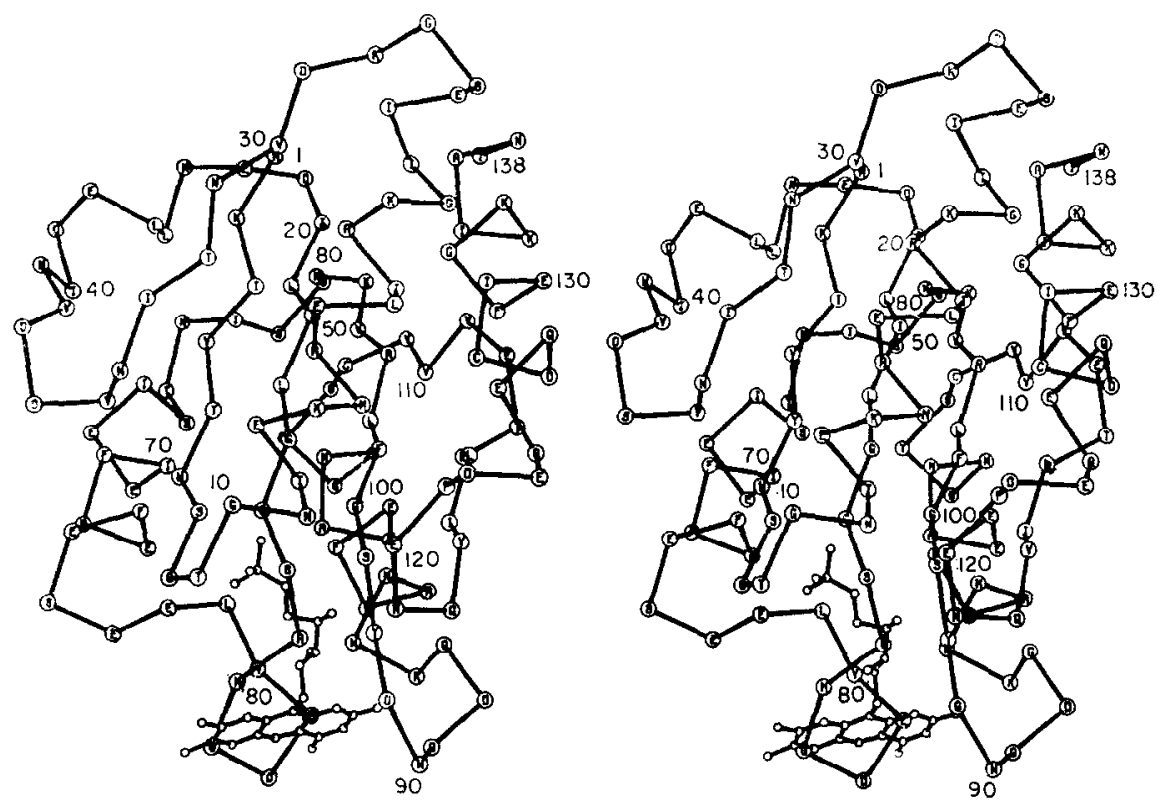

FIG. 4. A stereo drawing of the $\mathrm{C}_{a}$ and FMN atoms of flavodoxin semiquinone. The co-ordinates were idealized by real space refinement $(R=0 \cdot 247)$. The vertical direction in the Figure is parallel to $b$ and the view is down a line making an angle of $50^{\circ}$ with $-a^{*}$. Residues are identified by the one-letter code (see Fig. 3). 
The conformation of FMN and of those sequences has received particular attention throughout the structure analysis. The functional importance of the oxidationstate-dependent differences in the active center, which we observed on comparison of the isomorphous replacement maps, persuaded us to undertake refinement of both oxidized and semiquinone flavodoxins.

Differences in the electron density of Met56-Gly57-Asp58-Glu59, detected in isomorphous replacement maps of the oxidized and semiquinone flavodoxins, are shown in Figure 5. The shape of the density of Figure 5(a) suggests that in the semiquinone molecule, the carbonyl group of Gly57 points toward $\mathrm{N}(5)$ of the flavin ring ("up") whereas in oxidized flavodoxin (Fig. 5(b)) the carbonyl appears to point in the opposite direction ("down"). To test possible conformations of Gly57-Asp58, we conducted real space refinements with isomorphous replacement maps and different starting orientations $\uparrow$ (Ludwig et al., 1976; Darling, 1975). The 057 up conformation appeared to be the best interpretation for the density of Figure 5(a), but was unsatisfactory for oxidized flavodoxin.

In the following sections we consider the conformation of the FMN binding site of flavodoxin semiquinone, determined after refinement to an $R$ value of $0 \cdot 194$. Differences in the density at residues 57 to 58 persist after refinement of both oxidized and semiquinone flavodoxins, and comparison of current models reveals other smaller conformational changes.

\section{(ii) The protein conformation in the active center of flavodoxin semiquinone.}

The current co-ordinates for residues 54 to 59 and 87 to 91 , which contribute many of the FMN contacts, were determined by real space refinement. Atoms of either residues 56 to 59 or 89 to 91 were omitted from $\vec{F}_{\mathrm{c}}$ to produce $\left(2\left|F_{\mathrm{o}}\right|-\left|F_{\mathrm{c}}\right|\right)$ densities unbiased by any previous models (see Fig. 6(a)). Except for these deletions, the $\vec{F}_{\mathrm{c}}$ were computed with the parameters resulting from group least-squares refinement ( $R=0 \cdot 194$, Table 1). Starting co-ordinates for real space refinement of protein atoms (Smith, 1977) had the bond lengths and angles specified by Diamond's (1966) modelbuilding program. Residues 53 through 61 were refined versus the density shown in part in Figure 6(a), using a zone length of four and other control parameters as given in the legend to Figure 6. Because the densities corresponding to residues 57 and 58 have essentially the same shapes in isomorphous replacement and the final $\left(2|F|_{0}\right.$ - $\left.\left|F_{\mathrm{c}}\right|\right)$ maps (see Figs 5(a) and 6(a)), refinement starting with an inverted peptide unit, having the 057 down conformation of Fig. $5(b)$, was not repeated $\dagger$. The results of fitting a peptide with 057 near the flavin $N(5)$ are shown in Figure 6(a). The absence of features at the backbone of Gly57 and Asp58 in the $\left(\left|F_{0}\right|-\left|F_{c}\right|\right)$ difference map of Figure 6(b) confirms the interpretation of Figure 6(a); this map also verifies the orientation of the remaining atoms in residues 56 through 59 . In analogous computations for the sequence 87 to 91 , atoms of residues 89 to 91 were excluded from the structure factors, and the sequence 87 to 96 was refined versus the resulting $\left(2\left|F_{\mathrm{o}}\right|-\left|F_{\mathrm{c}}\right|\right)$ map. Co-ordinates for the sequence 7 to 12 were obtained by energy minimization sulssequent to group least-squares refinement (Table 1).

† It was anticipated that refinement would fail to invert the peptide unit (Diamond, 1974) and in fact, refinement versus the semiquinone density, begun with 057 down, produced only small shifts and resulted in an electron count of 0.05 for 057 , which was centered well outside the density of Fig. 5(a). 

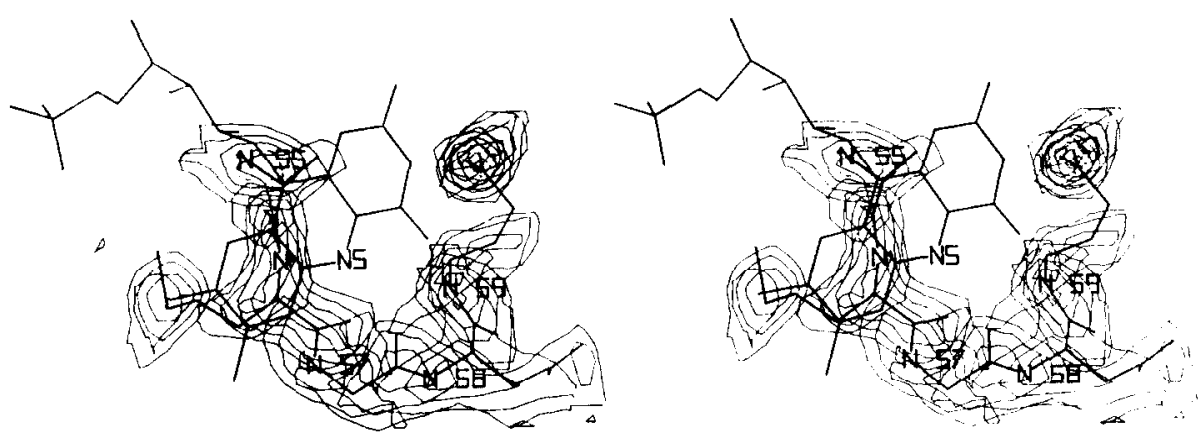

(a)
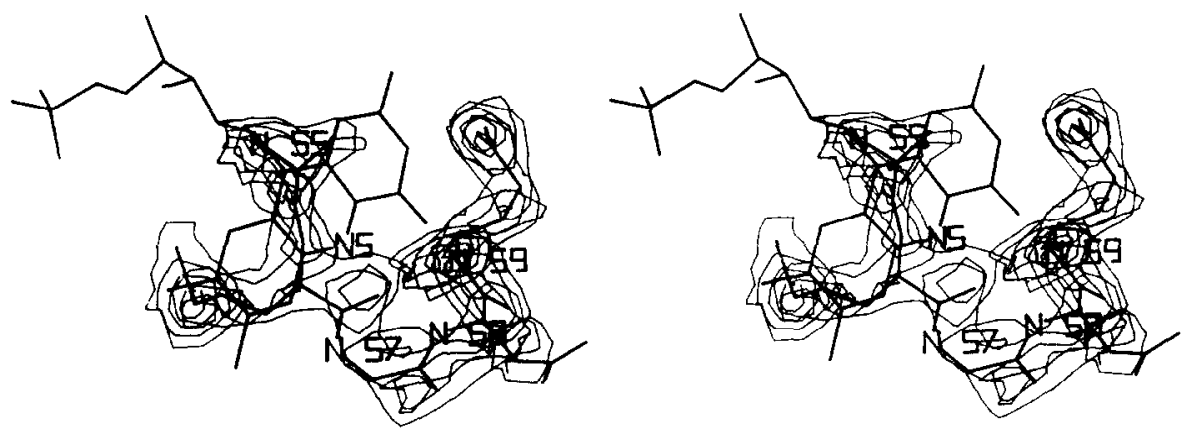

(b)

FIG. 5. Stereo views of electron densities corresponding to residues $\mathbf{5} 5$ to $\mathbf{6 9}$ (Ala-Met-GlyAsp-Glu) in the FMN binding region, with interpretations superimposed. Phases were determined by isomorphous replacement in both (a) and (b), and co-ordinates obtained by real space refine. ment. To show the relation of residues 55 to 59 to the FMN, the prosthetic group is also drawn, but without corresponding densities. (a) Flavodoxin semiquinone at $2 \cdot 0$ A resolution. 'The starting model for refinement had 057 pointing toward $\mathrm{N}(5)$, or "up". (b) Oxidized flavodoxin at 1.9 $\AA$ resolution. The interpretation at Gly57-Asp58 is the best fit for a peptide with 057 directed away from the FMN ring ("down").

In this and similar Figures (Figs 6 and 9), contours are drawn for density within $3 \AA$ of specified atoms. For clarity, no more than 5 contours have been included and the highest contour is well below the density at atomic centers. In (a) the first contour is at $0 \cdot 125$ e $\AA^{-3}$ and succeeding contours are at intervals of $0.25 \mathrm{e}^{-3}$. ('The density at the Met56 sulfur is $2 \cdot 18$ e $\AA^{-3}$.) In (b) the first contour is at 0.125 e $\AA^{-3}$ with intervals of $0.125 \mathrm{e} \AA^{-3}$.

The carboxyl group of Asp58 is not well-defined in either (a) or (b). Difficulties in orientation of the model are apparent in (b), where N57 and N58 lie in low density, and strong density below $\mathrm{C} \alpha 57$ is not occupied.

According to the present parameters, 71 protein atoms make intramolecular contacts of $4.0 \AA$ or less with one or more FMN atoms and five solvents (Table 3 ) are immediate neighbors of the FMN. The hinding site is displayed in Figure 8. The $C_{\alpha}$ of Asn119 is within 4.0 $\AA$ of $\mathrm{O}^{\prime}$ ' but this atom and intermolecular contacts have been omitted from the Figure. The distances and angles for a number of FMN-protein contacts are collected in Table 3 . From these data we can assign the most probable hydrogen-bonding interactions, recognizing the limitations imposed by uncertainties of about $0 \cdot 20 \AA$ in atomic positions. 

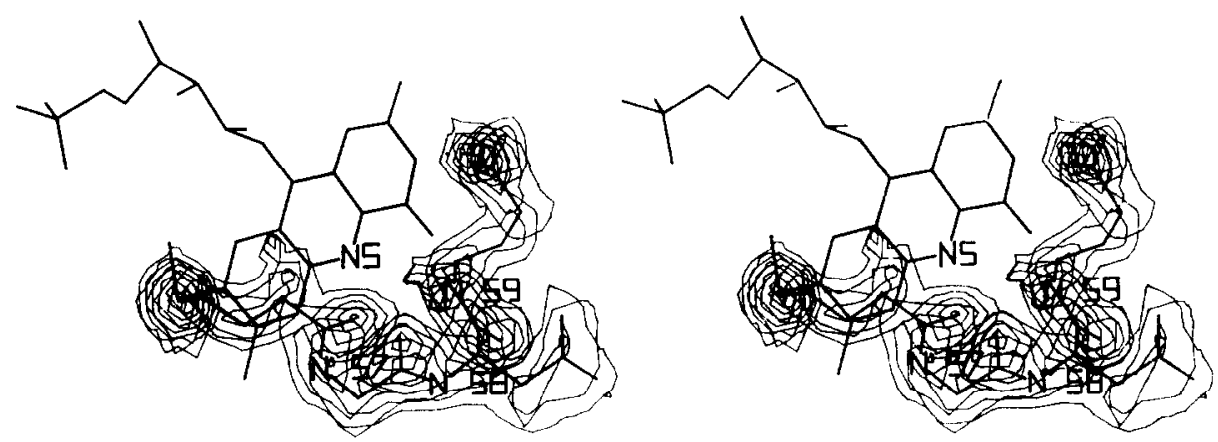

(a)
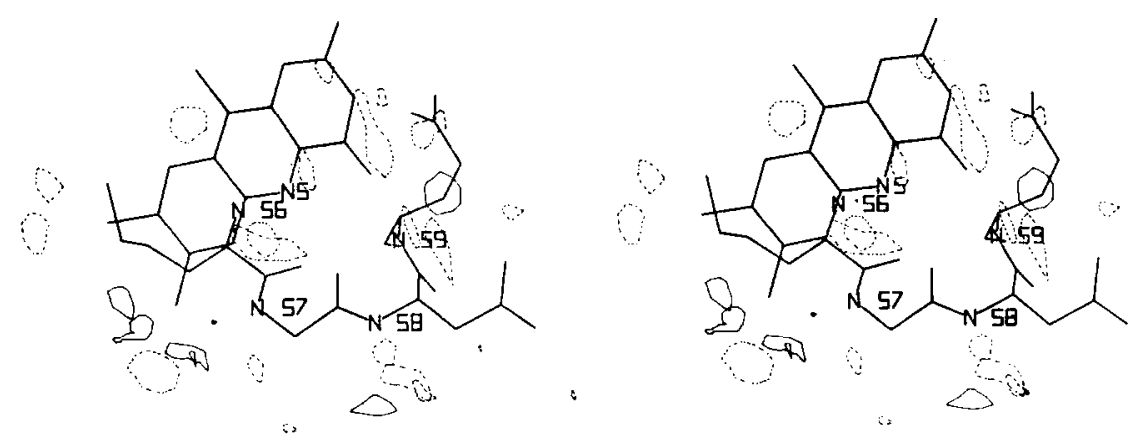

(b)

Fra. 6. The conformation of flavodoxin somiquinono in the bend consisting of residues 56 to 59. (a) A part of the Fourier synthesis with coefficients $\left(2\left|F_{\mathrm{o}}\right|-\left|F_{\mathrm{c}}\right|\right)$ exp $\left(i \alpha_{\mathrm{c}}\right)$. All atoms of residues 56 to 59 were omitted from $\vec{F}_{c}$, which were calculated from the parameters of Table 1 $(R-0 \cdot 194)$ (see Experimental and Methods for other details of $\left(2\left|F_{0}\right|-\left|F_{c}\right|\right)$ maps). The superposed model resulted from real space refinement of residues 53 to 61 , starting with 057 pointing toward $N(5)$. For refinement, all radii were held at $1.2 \AA$ and weights were: $\phi$ and $\psi, 3 \cdot 7 ; \omega, 0.5$; $\chi, 3 \cdot 2$; and $\tau, 0 \cdot 33$. The lowest contour is at $0 \cdot 30 \mathrm{e} \AA^{-3}$ and contour intervals correspond to $0 \cdot 30$ e $\AA^{-3}$. (b) A Fourier synthesis with coefficients $\left(|F|_{0}-|F|_{0}\right) \exp \left(i \alpha_{a}\right)$. Atoms of residues 56 to 59 were included in $\vec{F}_{\mathrm{c}}$. Terms between 5.0 and $1.8 \AA$ have been used when $I>2 \sigma$ and $F_{\mathrm{c}} / F_{\mathrm{O}}$ $>0.3$. Model is the same as in (a). Negative contours (__ _ — ) begin at $-0.125 e \AA^{-3}$, with intervals of $0.10 \mathrm{e} \AA^{-3}$; positive contours begin at $0.125 \mathrm{e}^{-3}$, with the same interval.

The geometry at 057 and the isoalloxazine $\mathrm{N}(5)$ favors a hydrogen bond involving the proton at $\mathrm{N}(5)$; the $\mathrm{O}$ to $\mathrm{N}$ distance is $2.80 \AA$ and the $\mathrm{O}-\mathrm{H}-\mathrm{N}$ atoms are almost in line. Overlap with the $\mathrm{sp}^{2}$ electrons of 057 is less than would be the case if the peptide unit and the isoalloxazine ring were coplanar. At the same time, the formal positive charge on $\mathrm{N}(5)$ in the neutral semiquinone (Fig. 13) enhances the $\mathrm{N}(5)-057$ interaction. The close approach of 057 and $O(4)$ must be associated with an unfavorable coulombic repulsion (see Discussion).

Our current co-ordinates suggest that a hydrogen bond between N59 and $O(4)$ is more likely than formation of the $3_{10}$ hydrogen bond between N59 and O56. Torsion angles for the backbone in the reverse bend at 56 to 59 are listed in Table 4 . 


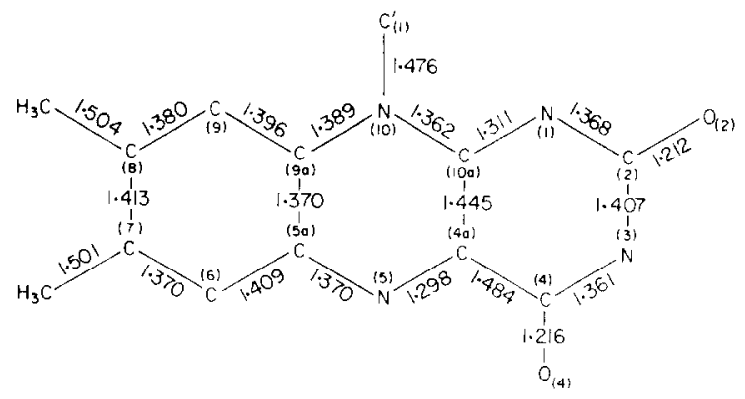

(a)

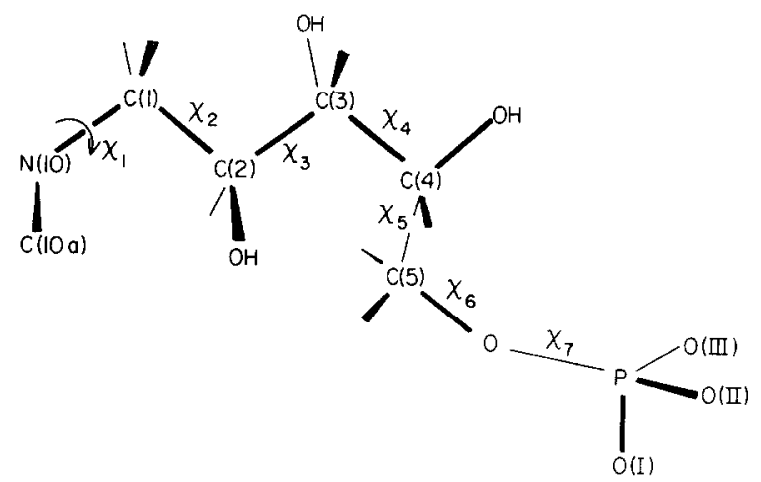

(b)

FIG. 7. The model isoalloxazine (a) and ribityl phosphate chain (b) used in fitting electron densities. The bond lengths in (a) correspond to the ideal isoalloxazine of Wang \& Fritchie (1973) (see Experimental and Methods). In (b), for the purpose of assigning dihedral angles, the backbone begins at $\mathrm{C}(10 \mathrm{a})$ and terminates at $\mathrm{O}(\mathrm{I})$. The direction of positive rotation is illustrated for $\chi_{1}$; dihedral angles are taken to be zero when the adjacent main-chain bonds are cis. The bond lengths for ribityl phosphate are: $\mathrm{C}-\mathrm{OH}, 1.43 \AA ; \mathrm{C}-\mathrm{C}, 1.524 \AA ; \mathrm{N}(10)-\mathrm{C}\left(1^{\prime}\right), 1.486 \AA ; \mathrm{C}\left(5^{\prime}\right)-$ $\mathrm{O}\left(5^{\prime}\right), 1.425 \AA ; \mathrm{O}\left(5^{\prime}\right)-\mathrm{P}, 1.61 \AA$; and terminal $\mathrm{P}-\mathrm{O}, 1.51 \AA$ (Kim et al., 1969; Wane \& Fritchie, 1973; Sundaralingam \& Jensen, 1965; Watson \& Kennard, 1973). In the text, ribityl atoms are distinguished by primes.

For comparison, the angles predicted for ideal $3_{10}$ reverse bends (Venkatachalam, 1968; Chandrasekaran et al., 1973) have been included. One consequence of the deviations from the ideal values is the poor overlap for formation of the $3_{10}$ hydrogen bond. The $\mathrm{C}-\mathrm{O}-\mathrm{N}$ angle is $154^{\circ}$; the distance separating $\mathrm{O} 56$ and $\mathrm{N59}$ is $3.09 \AA$; and the $\mathrm{H}-\mathrm{N}-\mathrm{O}$ angle is $62^{\circ}$. On the other hand, the distance between $\mathrm{N} 59$ and the flavin $\mathrm{O}(4)$ is $2.83 \AA$ with $\mathrm{C}-\mathrm{O}-\mathrm{N}$ and $\mathrm{H}-\mathrm{N}-\mathrm{O}$ angles at $145^{\circ}$ and $20^{\circ}$, respectively.

Other potential hydrogen-bonding partners of the isoalloxazine ring are the backbone amides of residues 89 through 91 , and the side-chain of Glu59. Although the distance from $\mathrm{N}(3)$ to the carboxyl oxygen of Glu59 is $2 \cdot 89 \AA$ and the $\mathrm{H}-\mathrm{N}-\mathrm{O}$ angle is $6^{\circ}$, the large angle between the carboxylate and flavin planes will undoubtedly diminish the covalent component of the interaction between $\mathrm{HN}(3)$ and the Glu59 oxygen. Table 3 and Figure 8 suggest that NH90 fails to form any hydrogen bond to the flavin, whereas the amide of Gly9l seems to interact well with $O(2)$. No clear choice for the NH89 acceptor can be distinguished from the data of Table 3; a hydrogen bond may be formed with either $\mathrm{N}(1)$ or $O(2)$. 
Ribity] oxygens $02^{\prime}$ and $04^{\prime}$ hydrogen bond to protein atoms 055 and $\mathrm{N}$ (or O) 11 $\delta$, respectively; the geometry for the $0 \mathrm{H} 87$ to $04^{\prime}$ interaction is also acceptable. 'Two solvents and the carbonyl oxygen of Ile24 from an adjoining molecule are the nearest neighbors of $\mathrm{O3}^{\prime}$. The three phosphate oxygens are involved in an intricate network of contacts with solvent and protein atoms; each oxygen has at least three potential hydrogen-bond donors (assuming the phosphate to be present as the dianion at pH 6-8). Each succeeding backbone amide, from Gly8 to Thr12, adjoins a phosphate oxygen, and the four side-chain hydroxyls of residues Ser7, Thr9, Thr12 and Ser54 are all within $2.90 \AA$ of one or other phosphate oxygen. Of the possible hydrogen

TABLE 3

Interactions between FMN semiquinone and apoprotein

A. Pairs capable of hydrogen bonding $\dagger$

\begin{tabular}{|c|c|c|c|c|}
\hline FMN atom & Protein (or solvent) & Distance $(\AA)$ & Angle & (deg) \\
\hline \multirow[t]{5}{*}{$O I$} & Gly8 $\mathrm{N}$ & $2 \cdot 73$ & $8 \underline{\mathrm{H}} \mathrm{N}-\mathrm{N}-\mathrm{OI}$ & 11 \\
\hline & & & P.OI-8N & 110 \\
\hline & Ser54 O $\gamma$ & $2 \cdot 89$ & P-OI-540 $\gamma$ & 108 \\
\hline & & & OI $-54 \mathrm{O} \gamma-54 \mathrm{C} \beta$ & 105 \\
\hline & W I & $2 \cdot 75$ & P-OI-W 1 & 131 \\
\hline \multirow[t]{6}{*}{ OII } & Ser7 $0 \gamma$ & $2 \cdot 77$ & P-OII-7O $\gamma$ & 110 \\
\hline & & & $\mathrm{OH}-7 \mathrm{O} \gamma-7 \mathrm{C} \beta$ & 109 \\
\hline & Thr12 Oy & $2 \cdot 81$ & P-OI- $120 \gamma$ & 139 \\
\hline & & & $\mathrm{OII}-12 \mathrm{O} \gamma-12 \mathrm{C} \beta$ & 93 \\
\hline & Thr12 N & $2 \cdot 87$ & $12 \underline{H N}-12 \mathrm{~N}-\mathrm{OII}$ & 9 \\
\hline & & & P-OII-12N & 133 \\
\hline \multirow[t]{7}{*}{ OIII } & Thr9 O $\gamma$ & $2 \cdot 65$ & P.OIII-90 $\gamma$ & 151 \\
\hline & & & OIII $-9 \mathrm{O} \gamma \cdot 9 \mathrm{C} \beta$ & 110 \\
\hline & Thr9 N & $2 \cdot 80$ & $9 \underline{\mathrm{H}} \mathrm{N}-9 \mathrm{~N}-\mathrm{OIII}$ & 23 \\
\hline & & & P.OHI.9N & 119 \\
\hline & Gly $10 \mathrm{~N}$ & 3.01 & $10 \underline{\mathrm{H}}-10 \mathrm{~N} \cdot \mathrm{OIII}$ & 46 \\
\hline & & & P.OIII-10N & 137 \\
\hline & Asnll N & $3 \cdot 14$ & $11 \mathrm{HN}-11 \mathrm{~N}-\mathrm{OIII}$ & 15 \\
\hline \multirow[t]{5}{*}{$\mathrm{O}^{\prime}$} & Asn $11 \mathrm{~N}($ or 0$) \delta$ & $2 \cdot 61$ & $11 \underline{\overline{\mathrm{H}}} \mathrm{N} \delta-11 \mathrm{~N} \delta-\mathrm{O} 4^{\prime}$ & 5 \\
\hline & & & $11 \overline{\mathrm{N}}(\mathrm{O}) \delta-\mathrm{O}^{\prime}-\mathrm{C} 4^{\prime}$ & 139 \\
\hline & Ser87 O $\gamma$ & $2 \cdot 85$ & $870 \gamma-\mathrm{O4}^{\prime}-\mathrm{C4}^{\prime}$ & 97 \\
\hline & & & $04^{\prime}-870 \gamma-87 \mathrm{C} \beta$ & 119 \\
\hline & W 4 & 3.01 & $\mathrm{~W} 4-\mathrm{O}^{\prime}-\mathrm{C}^{\prime}$ & 114 \\
\hline \multirow[t]{2}{*}{$\mathrm{O3}^{\prime}$} & $\mathrm{W}_{2}$ & $2 \cdot 81$ & $\mathrm{~W} 2-\mathrm{O3}^{\prime} \cdot \mathrm{C} 3^{\prime}$ & 125 \\
\hline & W 4 & $2 \cdot 88$ & $\mathrm{~W}^{\prime}-\mathrm{O}^{\prime}-\mathrm{C} 3^{\prime}$ & 110 \\
\hline \multirow[t]{2}{*}{$\mathrm{O}^{\prime}$} & Ala55 O & $2 \cdot 61$ & $\mathrm{C} 2^{\prime}-\mathrm{O} 2^{\prime}-550$ & 112 \\
\hline & & & $02^{\prime}-550.55 \mathrm{C}$ & 127 \\
\hline \multirow[t]{2}{*}{$\mathrm{O}(4)$} & Glu59 N & $2 \cdot 83$ & $59 \underline{\mathrm{H} N}-59 \mathrm{~N}-9(4)$ & 20 \\
\hline & & & $C(\overline{3)}-\mathrm{O}(4)-59 \mathrm{~N}$ & 145 \\
\hline \multirow[t]{7}{*}{$\mathrm{O}(2)$} & Gly91 N & $2 \cdot 88$ & 9l-HN-91N-O(2) & 15 \\
\hline & & & $91 \bar{N}-\mathrm{O}(2)-\mathrm{C}(2)$ & 125 \\
\hline & Gly89 N & $2 \cdot 98$ & $89 \mathrm{HN}-89 \mathrm{~N}-\mathrm{O}(2)$ & 17 \\
\hline & & & $89 \overline{\mathrm{N}}-\mathrm{O}(2) \cdot \mathrm{C}(2)$ & 100 \\
\hline & $\operatorname{Trp} 90 \mathrm{~N}$ & $3 \cdot 23$ & $90 \mathrm{HN}-90 \mathrm{~N}-\mathrm{O}(2)$ & 51 \\
\hline & & & $90 \overline{\mathrm{N}}-\mathrm{O}(2)-\mathrm{C}(2)$ & 103 \\
\hline & W 3 & $3 \cdot 26$ & W3-O(2)-C(2) & 117 \\
\hline $\mathrm{N}(1)$ & Gly89 N & $3 \cdot 04$ & $89 \underline{\mathrm{H}}-89 \mathrm{~N}-\mathrm{N}(1)$ & 33 \\
\hline \multirow[t]{2}{*}{$\mathrm{N}(3)$} & Gly59 O $\epsilon$ & $2 \cdot 71$ & $\underline{H} \bar{N}(3)-N(3)-590 \epsilon$ & 6 \\
\hline & & & $\overline{\mathrm{N}}(3)-590 \epsilon-59 \mathrm{C} \delta$ & 118 \\
\hline \multirow[t]{2}{*}{$\mathbf{N}(5)$} & Gly57 O & $2 \cdot 80$ & $\underline{\mathrm{H} N}(5)-\mathrm{N}(5)-57 \mathrm{O}$ & 7 \\
\hline & & & $\overline{\mathrm{N}}(5)-570-57 \mathrm{C}$ & 140 \\
\hline
\end{tabular}


TABLE 3 (continued)

B. Short contacts not involving hydrogen bonds

\begin{tabular}{|c|c|c|}
\hline FMN utom & Protein atom & Distance $(\AA)$ \\
\hline OI & $8 C_{\alpha}$ & $3 \cdot 38$ \\
\hline OII & $12 C \beta$ & $3 \cdot 22$ \\
\hline OIII & $9 \mathrm{C} \alpha$ & $3 \cdot 33$ \\
\hline$O 5^{\prime}$ & $54 \mathrm{C} \beta$ & $2 \cdot 25$ \\
\hline $\mathrm{C}^{\prime}$ & $870 \gamma$ & $3 \cdot 34$ \\
\hline$O 2^{\prime}$ & $88 C \alpha$ & $3 \cdot 40$ \\
\hline$C(9 a)$ & 550 & $3 \cdot 25$ \\
\hline$N(10)$ & 550 & $3 \cdot 13$ \\
\hline$C(10 a)$ & 550 & $3 \cdot 29$ \\
\hline$C(2)$ & $89 \mathrm{~N}$ & $3 \cdot 40$ \\
\hline$O(4)$ & 570 & $3 \cdot 15$ \\
\hline$C(4 a)$ & $90 \mathrm{C} \zeta 2$ & $3 \cdot 30$ \\
\hline$N(5)$ & $90 \mathrm{C \zeta} 2$ & $3 \cdot 33$ \\
\hline$C(6)$ & $57 \mathrm{~N}$ & $3 \cdot 32$ \\
\hline$c(8)$ & $56 \mathrm{~S}$ & $3 \cdot 87$ \\
\hline (c7-methyl) & W 5 & $3 \cdot 80$ \\
\hline
\end{tabular}

$\dagger$ Except for solvents, only contacts shorter than $3 \cdot 25 \AA$ are listed.
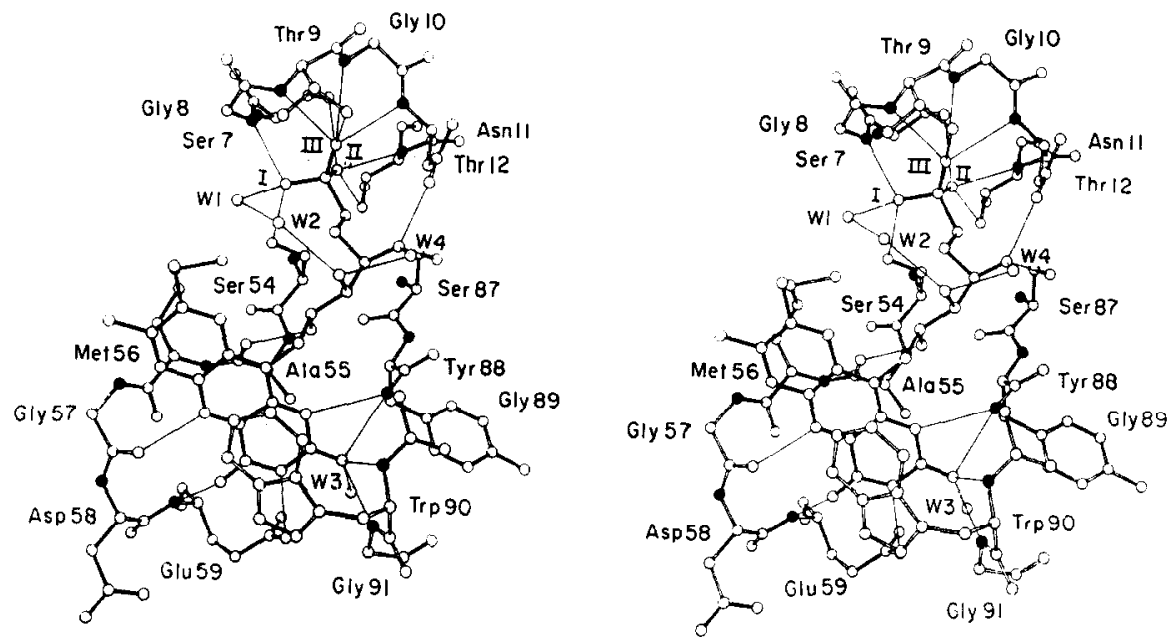

FIG. 8. A stereo drawing depicting some of the FMN-protein interactions in flavodoxin from Clostridium MP. The flavin mononucleotide is drawn with solid bonds; identification and number. ing of the FMN atoms is given in Fig. 7. Protein atoms are connected by open bonds and nitrogen atoms are filled in. Thin lines designate contacts shorter than $3 \cdot 25 \AA$, involving FMN hetero. atoms and nitrogen or oxygen atoms of the protein. Only some of these interactions entail hydrogen bonding (see Table 3 and text). No intermolecular interactions are included in this Figure (see Fig. 12). Positions of the Ser7 and Gly8 labels should be interehanged.

bonds, the "weakest" appear to be those to OIII; in particular, tho $H-N \cdot O$ angle for Glyl0 NH to OIII exceeds the maximum value of 30 to $35^{\circ}$ associated with hydrogen bonding.

Some of the shortest non-bonded contacts between atoms incapable of hydrogen bonding are included in Table 3 . The list has been restricted to isoalloxazine atoms, 


\section{TABLE 4}

Backbone torsion angles for residues 57 to 58 (deg.)

\begin{tabular}{|c|c|c|c|c|c|c|}
\hline & $\phi_{b_{i}}$ & & $\psi_{07}$ & $\omega$ & $\phi_{58}$ & $\psi_{58}$ \\
\hline Flavodoxin semiquinone & 10 & & $-\ldots 137$ & 164 & 77 & 80 \\
\hline Type I, $3_{10}$ bend & 50 to & 70 & 30 to 50 & & 90 to -110 & 10 to 40 \\
\hline Oxidized flavodoxin & 10 & & 59 & & 80 & 53 \\
\hline Type II, $3_{10}$ bend & -60 & & 100 to 130 & 172 & 60 to 80 & 0 to 40 \\
\hline
\end{tabular}

and with the exception of the Met56 sulfur, to distances less than $3 \cdot 4 \AA$. The $C \zeta 2$ of Trp90 is only $3 \cdot 3 \AA$ from $\mathrm{C}(4 \mathrm{a})$ and $\mathrm{N}(5)$. Because the indole and flavin rings are inclined to one another at an angle of $19^{\circ}$, no other atoms of Trp90 and the flavin ring approach more closely than the customary distance for aromatic rings of $3 \cdot 4 \AA$. None of the remaining FMN-protein distances is shorter than the usual "allowed" values (Scheraga, 1968).

\section{(iii) The conformation of $F M N$ after refinement}

The results of fitting FMN to a $\left(2\left|F_{\mathrm{o}}\right|-\left|F_{c}\right|\right)$ map by real space refinement are displayed in Figure 9. Construction of the FMN model (Fig. 7) has been discussed in Experimental and Methods. During real space refinement, the isoalloxazine ring was permitted to bend about the $\mathrm{N}(10)-\mathrm{N}(5)$ direction, with the atoms in each wing kept coplanar. Crystal structures of model flavins (e.g. Wang \& Fritchie, 1973) show that this treatment accounts for the major deviations of ring atoms from planarity. Although neither wing is perfectly planar in accurately determined structures of
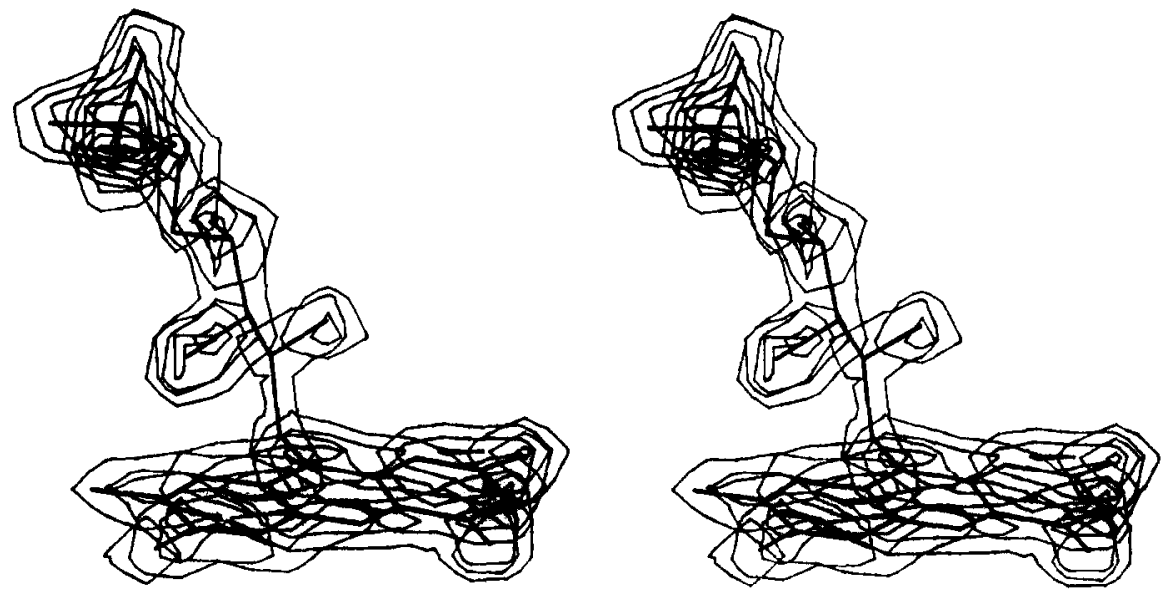

FIG. 9. Interpretation of electron density corresponding to FMN in flavodoxin semiquinone. Contours are from a $\left(\left.2\left|F_{0}-\right| F\right|_{0}\right)$ map with FMN atoms omitted from $\vec{F}_{\mathrm{c}}$, which were calculated using parameters of Table $1(R=0.194)$. The minimum contour level is 0.40 e $\AA^{-0}$; contours at intervals of 0.40 e $\AA^{-3}$. The model represents co-ordinates determined by real space refinement. The isoalloxazine ring is bent by $-2 \cdot 5^{\circ}$ about the $N(10)-N(5)$ direction. The bending, which is too small to be perceptible in this drawing, tends to bring the dimethylbenzene (left) end of the ring down toward the bottom of the Figure. The torsion angles and details of the refinement are given in Tables 5 and 6. 
isoalloxazines (Kierkegaard et al., 1971), for the resolution attainable with a protein a simple model limits the variables in a realistic fashion. The conformation of free isoalloxazine semiquinones has not been determined crystallographically as a result of difficulties with disproportionation of model flavin radicals, but measured spectra predict an essentially planar ring for the semiquinone radical (Land \& Swallow, 1969; Muiller et al., 1970; Eriksson \& Ehrenberg, 1973). In contrast, in a series of fully reduced $\mathrm{N}(1)$ or $\mathrm{N}(5)$-substituted model flavins, the bending about $\mathrm{N}(10)-\mathrm{N}(5)$ is pronounced, being of the order of $30^{\circ}$ (Kierkegaard et al., 1971; Werner \& Ronnquist, 1970; Norrestam \& von Glehn, 1972).

TABLE 5

Bending of the isoalloxazine ring in flavodoxin semiquinone

\begin{tabular}{lccc}
\hline Maps & $R$ & $\begin{array}{c}\text { Resolution } \\
(\AA)\end{array}$ & $\begin{array}{c}\text { Bending angle } \\
\text { (deg.) }\end{array}$ \\
\hline Isomorphous replacement & & $20 \cdot 0-\mathbf{2} \cdot 0$ & $-3 \cdot 9$ \\
$\left(2\left|F_{\mathrm{o}}\right|-\left|F_{\mathrm{c}}\right|\right)$ & $0 \cdot 285$ & $\mathbf{1 5 \cdot 0 - 2 \cdot 0}$ & $-\mathbf{4} \cdot \overline{\mathbf{i}}$ \\
$\left(2\left|F_{\mathrm{o}}\right|-\left|F_{\mathrm{c}}\right|\right)$ & $0 \cdot 194$ & $15 \cdot 0-1 \cdot 8$ & $-2 \cdot 5_{5}$ \\
\hline
\end{tabular}

† The torsion angle is defined by atoms $\mathrm{C}(10 \mathrm{a})-\mathrm{N}(10)-\mathrm{N}(5)-\mathrm{C}(5 \mathrm{a})$, with zero angle for a trans orientation.

Bending of the isoalloxazine ring has been calculated at several stages in the structure of flavodoxin semiquinone (Table 5). In all entries of Table 5 real space refinement was begun with a flat flavin ring, and the "stiffness paramcter" for flavin torsion was the same as for backbone $\phi$ and $\psi$ angles (Diamond, 1971). Fitting to the $1.8 \AA\left(2\left|F_{\mathrm{o}}\right|-\left|F_{\mathrm{c}}\right|\right)$ map was also determined starting from a model with a torsion angle of $-7 \cdot 4^{\circ}$; in this case the angle could be refined to $-2 \cdot 4^{\circ}$ (Smith, 1977). (A negative torsion angle corresponds to a movement away from the center of gravity of the protein.) The numerical results vary with the resolution and the quality of the phases. The "best" values, from maps with all 31 FMN atoms deleted from the phases, are $-2 \cdot 5^{\circ}$ for flavodoxin semiquinone and $0 \cdot 2^{\circ}$ for oxidized flavodoxin. None of the angles of Table 5 appreciably exceeds values reported for oxidized isoalloxazines, which are as large as $4 \cdot 1^{\circ}$ (Tonaka et al., 1967). We do not regard the bending of the protein-bound FMN semiquinone as significantly different from the angles for oxidized flavodoxin or for oxidized model flavins.

The several torsion angles along the ribityl side-chains are listed in Table 6 (see Fig. 7). They are comparable to values found in model structures such as ribitol (Kim et al., 1969) and riboflavin (Tonaka et al., 1967; Wade \& Fritchie, 1973) where the close contact between $\mathrm{O}^{\prime}$ and $\mathrm{O}^{\prime}$ in an extended chain is relieved by a rotation of $-120^{\circ}$ about $\mathrm{C3}^{\prime}-\mathrm{C} 4^{\prime}$ (Ludwig et al., 1975).

\section{(c) Comparisons of oxidized and semiquinone flavodoxins}

\section{(i) Packing and overall molecular conformation}

Repacking (as a rigid-body motion) of the molecules upon change of oxidation state is reponsible for substantial changes in the diffracted intensities. In Table 7 , the results of simple co-ordinate transformation are compared with the effects of 


\section{TABLe 6}

Bond and torsion angles for the ribityl phosphate group $\dagger$

\begin{tabular}{cccccc}
\hline Bond angle & $\begin{array}{c}\text { Semiquinone } \\
\text { (deg.) }\end{array}$ & $\begin{array}{c}\text { Oxidized } \\
\text { (deg.) }\end{array}$ & Torsion anglef & $\begin{array}{c}\text { Semiquinone } \\
\text { (deg.) }\end{array}$ & $\begin{array}{c}\text { Oxidized } \\
\text { (deg.) }\end{array}$ \\
\hline$\tau_{1}$ & 120 & 115 & $\chi_{1}$ & 98 & -175 \\
$\tau_{2}$ & 117 & 106 & $\chi_{2}$ & -178 & -173 \\
$\tau_{3}$ & 130 & 110 & $\chi_{3}$ & 63 & -170 \\
$\tau_{4}$ & 100 & 117 & $\chi_{4}$ & -156 & -170 \\
$\tau_{5}$ & 96 & 123 & $\chi_{5}$ & -58 & -166 \\
& & & $\chi_{6}$ & -54 \\
\hline
\end{tabular}

$\dagger$ Values differ somewhat from those reported after partial refinement (Ludwig et al., 1975). $\mathrm{C}^{\prime}$.

$\ddagger$ Defined in Fig. $7(\mathrm{~b})$. $\tau \mathrm{s}$ are bond angles at carbons along the ribityl "chain" from $\mathrm{Cl}$ " to

\section{TABLE 7}

\section{Effects of rigid-body transformations}

A. Initial adjustment of oxidized co-ordinates to semiquinone data

\begin{tabular}{|c|c|c|c|}
\hline Parameter set & Atoms ${ }^{a}$ & $R_{\mathrm{sq}}{ }^{\mathrm{b}}$ & $\begin{array}{l}\text { r.m.s. co-ordinate } \\
\text { difference }(\AA)\end{array}$ \\
\hline 1. Oxidizede & 883 & $0 \cdot 445$ & \\
\hline 2. Set 1 , transformed by expression (I) (Results) & 883 & $0 \cdot 403$ & $2-1 ; 0 \cdot 390$ \\
\hline $\begin{array}{l}\text { 3. Real space refinement of } 1 \text { versus semiquinone } \\
\text { density }^{\mathrm{d}}\end{array}$ & 883 & $0 \cdot 397$ & $\begin{array}{l}3-1 ; 0.561 \\
3-2 ; 0.572\end{array}$ \\
\hline
\end{tabular}

\section{B. Comparisons after refinement}

Parameter set
Atomg $^{e}$

$\begin{array}{ll}939 & 0.305 \\ 939 & 0.423 \\ 939 & 0.331\end{array}$

$0 \cdot 331$ r.m.s. co-ordinate difference $(A)$

4. Semiquinone; $R=0 \cdot 194$ of Table 1

5. Oxidized; $R=0.211$ of Table 1

6. Rigid-body transformation ${ }^{f}$
$5 \quad 4 ; 0.709$

$6-4 ; 0.458$

$6-5 ; 0 \cdot 536$

a FMN atoms and protein atoms initially positioned in the isomorphous replacement map of flavodoxin semiquinone. No solvents.

${ }^{\mathrm{b}} R$ factors calculated with $\left|F_{\mathrm{a}}\right|$ for the semiquinone; in $A, R$ is calculated with data from $5 \cdot 0$ to $2 \cdot 0 \AA$; in $B$, with data from 5.0 to $1.8 \AA$.

c Positions at the end of 4 difference Fourier cycles.

a Pluses determined by isomorphous replacement. For real space refinement the radii were $1 \cdot 2 \AA$; weights were: $\phi, \psi, 3 \cdot 7 ; \chi, 3 \cdot 2 ; \omega, 0 \cdot 5 ; \tau, 0 \cdot 33$. Zone length was 5 and margin 8 .

Solvents, FMN, and atoms of residues 56-59 and 89-91 have been subtracted from the calculated structure factors reported in Table 1.

I The Eulerian angles are $-56 \cdot 61^{\circ}, 1 \cdot 79^{\circ}$ and $56.95^{\circ}$, with rotation axes through the center of gravity, and parallel to $c, a^{* \prime}$ and $c^{\prime \prime} . d_{1}=-0.235 \AA, d_{2}=0.299 \AA, d_{3}=0.213 \AA$. 
refinements which also permit the oxidized and semiquinone molecules to adopt different conformations. Part A reports results obtained at the beginning of crystallographic refinement, using the co-ordinate transformation determined from superposition of the isomorphous replacement maps (Cox, 1967). The rigid body motion produces a decrease in $R$ almost as large as that effected by real space refinement. In part $B$, refined parameters were used in the several structure factor computations. The $R$ factor is indeed smaller when adjustment of individual atoms is allowed than when the whole molecule is moved as a unit. Nevertheless, rigid-body transformation produces a considerable decrease in $R$ and causes the co-ordinates to converge.

Detection of true conformational differences is complicated by the non-isomorphism which is sufficient to preclude use of maps with coefficients $\left(\left|F_{\mathrm{ox}}\right|-\left|F_{\mathrm{sq}}\right|\right) \exp \left(i \alpha_{\mathrm{sq}}\right)$, although these should be the most discriminating for revealing small local changes in conformation (Henderson, 1970). Comparisons of very similar molecules which do not form strictly isomorphous crystals have been performed in several ways: by subtraction of the electron densities after delermination of the relative orientation of the two maps (Muirhead et al., 1967), by correlation of the density at corresponding points in the molecular structure (Cohen et al., 1970), or by correlation of the density in the vicinity of assigned atomic positions (White et al., 1976). Because both oxidized and semiquinone flavodoxins had been refined, we compared model co-ordinates directly.

Differences attributable solely to rigid-body motion were removed by a co-ordinate transformation which minimizes the squares of the differences between corresponding atoms (Rossmann \& Argos, 1975). The transformation varies somewhat, depending on the choice of atoms presumed to be equivalent in the two structures. In one calculation, atoms of the polypeptide backbone, excepting residues 56 to 59 and 89 to 91 , were matched initially. Only one of these 524 atoms was found to differ in position by more than $1.5 \AA$ after rigid-body transformation, and was excluded from final determination of the transformation. The root-mean-square difference between the remaining 523 atoms of the polypeptide backbone was then $0 \cdot 308 \AA$. In a second calculation, atoms not located in one or other electron density map were eliminated from the initial matching; FMN and all other side and main-chain atoms were included, making a total of 989 of the 1104 non-hydrogen atoms in the protein. Twelve atoms were separated by more than $1.5 \AA$ after initial superposition of the models and the remaining atoms determined the transformation. The root-mean-square separation for these other 977 atoms was $0.385 \AA$.

The positions of main-chain atoms in oxidized and semiquinone flavodoxins are compared in Figure 10. Distances between atoms identically situated in the chemical sequence were calculated after the transformation which sought to match mainchain atoms only, and discrepancies for the four atoms of each residue were averaged. The differences imply alterations in the orientation of peptide units $†$. We may not assign significance to these differences unless they are substantially larger than the expected co-ordinate error. Thus if the estimated error in the location of a carbon atom is $0 \cdot 17 \AA$, the error in the difference of two positions will be $0 \cdot 24 \AA$ and differences of $0.5 \AA$ are at the $2 \sigma$ level. If an average discrepancy of $0.5 \AA$ for main chain atoms is considered significant, Figure 10 indicates a number of residues, 38,41 to 42,44 to 45 ,

† Peptides were not forced to be planar in the real spare and group lenst-squares refinements. After energy munimization (Table 1), the mean value of $\omega$ for the semiquinone structure was $179 \cdot 4^{\circ} \cdot 6 \cdot 7^{\circ}$. Extreme values were $165 \cdot 4^{\circ}$ and $200 \cdot 8^{\circ}$. 


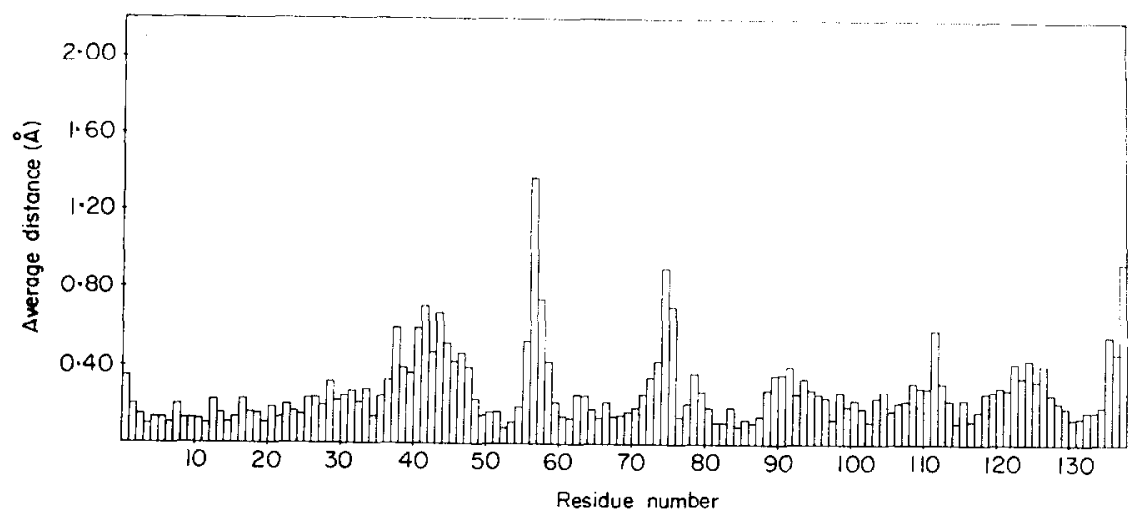

Fig. 10. A plot of distances between corresponding peptide units in oxidized and semiquinone forms of flavodoxin. Overall matching of the 2 models was achieved by transforming the coordinates for the semiquinono form bofore caloulation of distanoes botweon atoms (soe toxt). The average displacement of the 4 main-chain atoms is given for each residue (see Fig. 4 for the amino acid sequence). Co-ordinates were from the idealized parameter sets (Table 1). In oxidized flavodoxin, the carbonyl group of Gly57 has been assigned the conformation of Fig. 5(b).

56 to 58,75 to $76,112,136$ and 138 , where conformational differences between the oxidized and semiquinone structures may occur $\uparrow$. Many of these differences are found in residues which are exposed to solvent. In the sequences 37 to 48 and 73 to 78 , the electron density is relatively weak, and even at the present level of refinement, we are hesitant to assert that the differences in these residues represent real conformation changes. The peptide orientations in oxidized and semiquinone flavodoxins have been carefully re-cxamined by real space refinement of $\left(2\left|F_{\mathrm{o}}\right|-\left|F_{\mathrm{e}}\right|\right)$ maps, as already described, for residues 53 to 61 and 87 to 96 , but not for the remainder of the molecule.

\section{(ii) The FMN binding site}

Figure 11 provides a visual comparison of the flavin-binding sites in oxidized and semiquinone flavodoxins. The model for FMN and residues 56 to 59 and 89 to 91 of oxidized flavodoxin is based on refinements versus $\left(2\left|F_{\mathrm{o}}\right|-\left|F_{\mathrm{c}}\right|\right)$ maps, analogous to those of Figure 6(a) and Figure 7. The conformation of residues 57 and 58 in oxidized flavodoxin has not been unequivocally determined (see Discussion) but the conformation found in the semiquinone structure, with 057 pointing toward the flavin $\mathrm{N}(5)$, is inconsistent with the electron density of oxidized flavodoxin. The conformation of oxidized flavodoxin displayed in Figure 11 resulted from real space refinement of a model with the 57 to 58 peptide inverted (057 down).

Not only the backbone atoms from $\mathrm{C} 056$ to $\mathrm{C}_{\alpha} 58$, but also $055,068, \mathrm{C}_{\beta} 90$, and the side-chain of Met56, are displaced by more than $0.5 \AA$ in the two structures (Table 8). This variation is about twice the expected error for comparison of carbon positions (Experimental and Methods) and 1.6 times the root-mean-square difference of $0.31 \AA$ for main-chain atoms presumed to be identical. Smaller variations could affect the relative strengths of hydrogen-bonding of the flavin $\mathrm{O}(4)$ with NH59, of NH89 with $\mathrm{N}(1)$ or $\mathrm{O}(2)$, of $\mathrm{NH91}$ with $\mathrm{O}(2)$, and of $\mathrm{O4}^{\prime}$ with Asnll in the two oxidation states.

$\uparrow$ In an additional 13 residues, individual backbone atoms vary by more than $0.5 \AA$ in the two structures. 


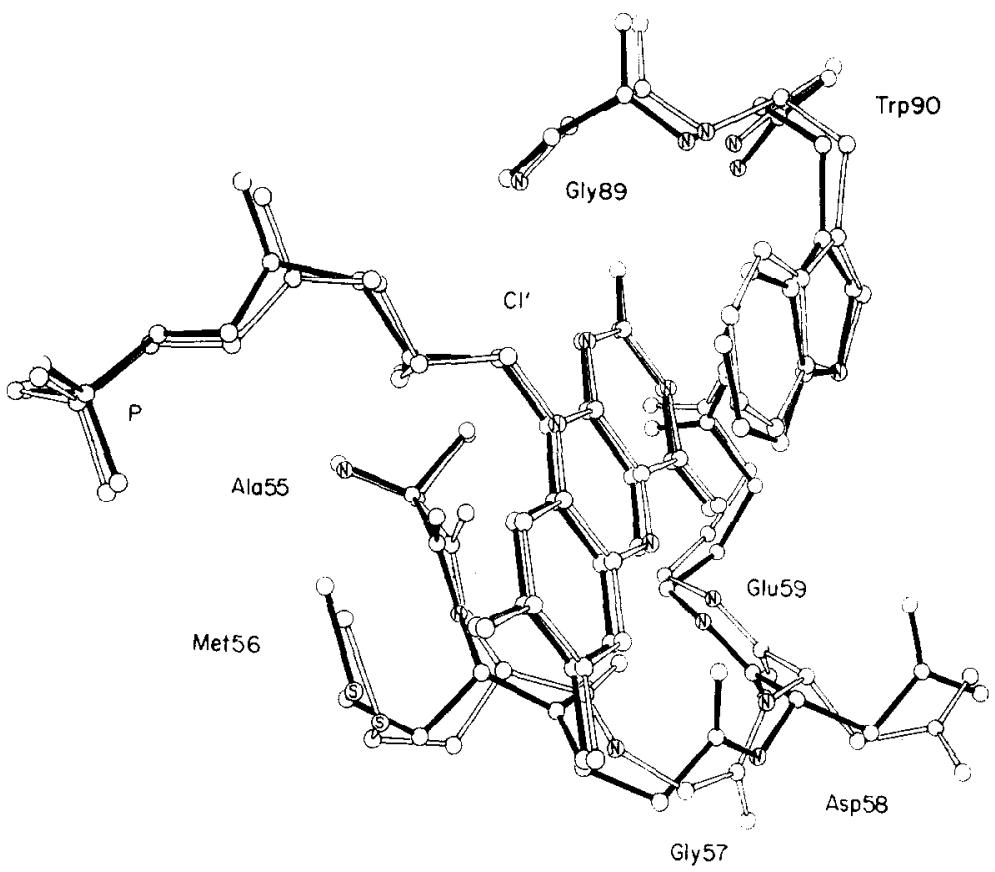

Fic, 11. FMN, residues 55 to 59 and 89 to 90 in the oxidized and semiquinone forms of flavodoxin from Clostridium $M P$. The semiquinone model is connected by solid bonds and the oxidized by open bonds. Co-ordinates for the semiquinone atoms have been transformed to yield the best fit of equivalent backbone atoms in the 2 oxidation states (see text for additional details). The drawing, therefore, shows co-ordinate differences relative to an "average" apoprotein backbone. Distances separating equivalent atoms are recorded in Table 8. (Positions of the Asp58 carboxyl group are not well-defined in either structure.)

\section{TABLE 8}

Comparison of semiquinone and oxidized flavodoxins after refinement: co-ordinate differences after superposition of models $\dagger$

\begin{tabular}{llll}
\hline Atom & Difference $(\AA)$ & Atom & Difference $(\AA)$ \\
\hline $\mathrm{P}$ & 0.18 & $57 \mathrm{C} \alpha$ & 0.55 \\
$04^{\prime}$ & 0.47 & $57 \mathrm{C}$ & 1.02 \\
$\mathrm{C} 4^{\prime}$ & 0.45 & $57 \mathrm{O}$ & 3.35 \\
$55 \mathrm{O}$ & 0.56 & $58 \mathrm{~N}$ & 1.11 \\
$56 \mathrm{C} \beta$ & 0.56 & $58 \mathrm{C} \alpha$ & 0.57 \\
$56 \mathrm{C} \gamma$ & 0.60 & $59 \mathrm{~N}$ & 0.42 \\
$56 \mathrm{~S}$ & 0.61 & 890 & 0.63 \\
$56 \mathrm{C}$ & 0.53 & $90 \mathrm{C} \zeta 3$ & 0.56 \\
$56 \mathrm{O}$ & 0.65 & $90 \mathrm{C} \beta$ & 0.51 \\
$57 \mathrm{~N}$ & 0.54 & $91 \mathrm{~N}$ & 0.45 \\
\hline
\end{tabular}

+ Co-ordinates were obtained by real space refinement versus $\left(2\left|F_{\mathrm{o}}\right|-\left|\boldsymbol{F}_{\mathrm{c}}\right|\right)$ maps. 
The peripheral ring atoms (Cє3, C $\zeta 3$, and $\mathrm{C} \eta 2$ ) of Trp90 are displaced by more than $0.4 \AA$ on oxidation. The errors in positioning atoms of large rigid groups, such as Trp or isoalloxazine, are expected to be smaller than for other atoms. Co-ordinates for Trp90 in oxidized and semiquinone flavodoxins have been examined after group refinement in reciprocal space, and after real space fitting of $\left(2\left|F_{\mathrm{o}}\right|-\left|F_{\mathrm{c}}\right|\right)$ maps. Positions for the ring and $\mathrm{C}_{\beta}$ atoms obtained by the two methods vary by a rootmean-square $\Delta$ of $0.24 \AA$ in the oxidized and $0.09 \AA$ in the semiquinone structure. However, co-ordinate differences as a function of oxidation state are larger: $0 \cdot 41 \AA$ after group refinement and $0 \cdot 34 \AA$ after real space refinement. Both methods reveal a similar shift of Trp90 as a result of flavin reduction. We conclude that the differences at $\operatorname{Trp} 90$ (Fig. 11) are probably real.

Comparison of the active centers shows that the presence of the hydrogen bond to $\mathrm{N}(5)$ in flavodoxin semiquinone is a distinctive feature. No other all-or-none differences in hydrogen bonding are clearly established by comparison of the oxidized and semiquinone models. The only other unique interaction would be a hydrogen bond between $\mathrm{NH58}$ and $\mathrm{O}(4)$ in oxidized flavodoxin, an interaction which is impossible in the semiquinone species (Figs 6 and 11). However, from the oxidized co-ordinates corresponding to Figure 11, the $\mathrm{N}-\mathrm{O}$ distance proves to be $3.52 \AA$ and the $\mathrm{H}-\mathrm{N}-\mathrm{O}$ angle, $44^{\circ}$.

\section{(iii) Intermolecular contacts at the FMN-binding site}

The drawing of Figure 12 shows the neighbors closest to the active center in flavodoxin semiquinone. Contacts in the vicinity of the flavin-binding site are generated by three different symmetry operations: a $2_{1}$ axis parallel to $b$ which brings
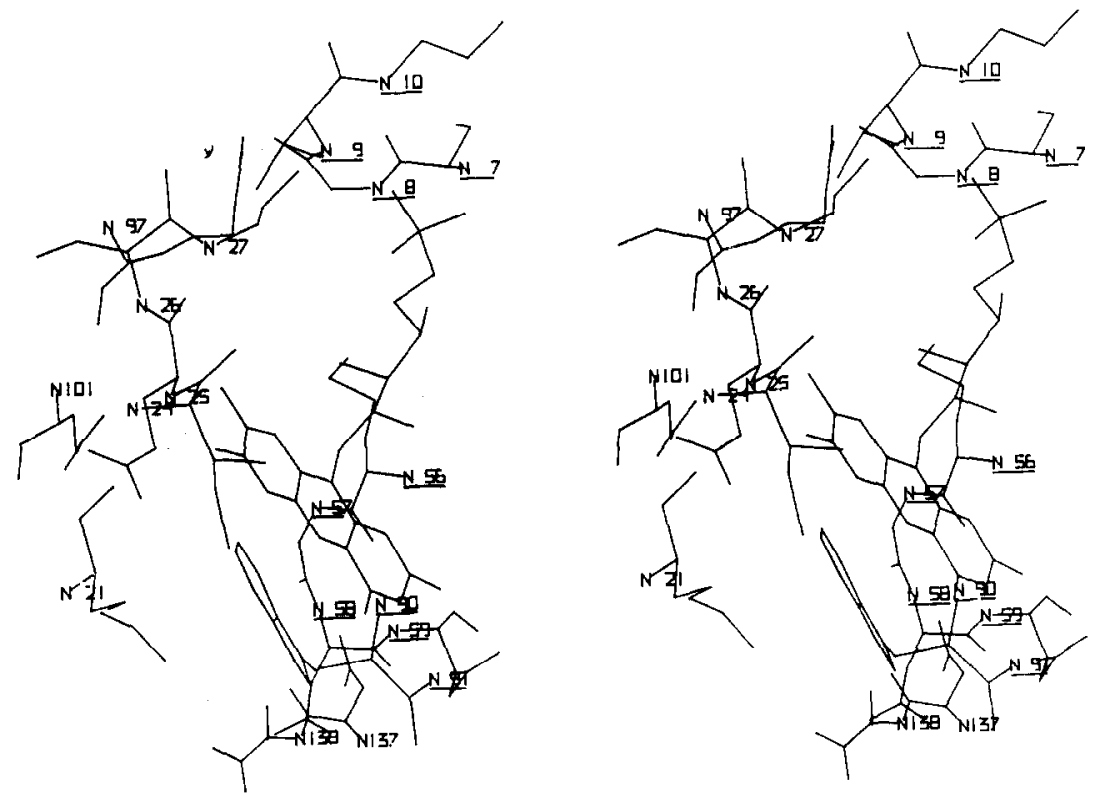

FIG. 12. A drawing showing intermolecular contacts at the FMN binding site of flavodoxin semiquinone. The underlined residue numbers refer to sequences in the molecule to which the FMN is attached. The close approach of Glu101 and Glu25 is surprising, but there is no chemical evidence to suggest that one or other of these residues is an amide. 
Lys21, Ile24, Glu25 and Gly27 near the flavin; a $2_{1}$ axis parallel to $a$ which causes Asn137 of another neighbor to approach Asp58; and a $3_{1}$ axis which produces contacts with Asp92, Lys94, Arg97 and Glu101 from a third neighbor. The closest approaches (less than $4 \AA$ ) are made by atoms of residues $21,24,25,101$ and 137. The interactions vary between oxidized and semiquinone flavodoxins in a complex way, because both conformational differences and rigid-body motion influence the intermolecular contacts. From the standpoint of the conformation and packing changes which accompany reduction of the FMN, the interaction of AsnI37 is the most interesting. In oxidized flavodoxin the Asn137 side-chain amide may form a hydrogen bond to $\mathrm{O(57)}$; the relative orientations of Asn137 and the bend at Gly57 and Asp58 change appreciably on formation of the semiquinone.

\section{Discussion}

(a) Methods of structure determination and comparison

Our objective has been the determination of the structure of flavodoxin semiquinone, particularly the arrangement of the FMN binding site, at a higher resolution and accuracy than heretofore. Although the semiquinone (radical) form of clostridial flavodoxin provided the first model of the molecule at $3 \cdot 25 \AA$ resolution (Andersen et al., 1972), subsequent effort was directed to solution of oxidized flavodoxin at $1.9 \AA$ (Burnett et al., 1974).

Extension of the semiquinone structure beyond $3 \cdot 25 \AA$ resolution has proceeded in two stages, first by isomorphous replacement, and then by refinement. Phases to $2 \cdot 0 \AA$ were determined solely by isomorphous replacement, deliberately excluding any information from the model for oxidized flavodoxin. This approach was elected because early in our study of flavodoxin from Clostridium MP, we had found that maps with coefficients $\left(\left|F_{\mathrm{sq}}\right|-\left|F_{\mathrm{ox}}\right|\right) \exp \left(i \alpha_{\mathrm{ox}}\right)$ showed numerous features throughout the molecule, consistent with small co-ordinate shifts by many atoms. The appearance of such maps, combined with the $R_{\mathrm{I}}=\left(\sum\left|I_{\mathrm{ox}}-I_{\mathrm{sq}}\right|\right) /\left(\sum\left(I_{\mathrm{ox}}+I_{\mathrm{sq}}\right)\right)$ of $0 \cdot 33$, deterred us from attempts at direct use of the phases from oxidized flavodoxin. The $2 \AA$ isomorphous replacement map provided an initial model of flavodoxin semiquinone; co-ordinates were obtained by real space refinement using the isomorphous replacement map and atoms chosen from the oxidized model. The structure was then subjected to further crystallographic refinement and the resolution simultaneously extended to $1.8 \AA$. Manual adjustment and addition of atoms, in accord with difference Fourier maps, has been crucial in evolving the semiquinone model. The co-ordinates of FMN and atoms of the flavin binding site were established after refinement to $R=0.194$ by fitting $\left(2\left|F_{\mathrm{o}}\right|-\left|F_{\mathrm{c}}\right|\right)$ maps in which selected atoms of the active center had been deleted from the $\vec{F}_{\text {c }}$ ("deletion" maps). The validity of the model at other positions relies on the absence of features in $\left(\left|F_{\mathrm{o}}\right|-\left|F_{\mathrm{c}}\right|\right)$ maps.

After refinement of oxidized and semiquinone flavodoxins to discrepancy indices of 0.211 and $0 \cdot 194$, respectively, we can define more precisely the non-isomorphism of the two structures. Phase angles for the oxidized and semiquinone structures differ, on the average, by $44^{\circ}$ for the non-idealized parameters of Table 1 . The rootmean-square distance between 939 of the total 1104 chemically equivalent atoms, positioned in their unit cells, is $0.71 \AA$ (Table 7 ); rigid-body transformation involving rotation of about $2^{\circ}$ and a shift of $0.44 \AA$ in the center of gravity reduces this spatial discrepancy to $0.46 \AA$. The magnitude of the effects attributable to packing changes, 
in contrast with the small observed conformation changes, suggests that alternate routes to the structure determination might have been feasible. For example, Anderson (1975) encountered a related case of non-isomorphism in comparing crystals of deoxyhemoglobin with crystals of carbonmonoxy (T-state) hemoglobin Kansas, and found the necessary co-ordinate transformations from the rotation and translation functions.

The most obvious differences between the oxidized and semiquinone molecules occur at the peptide linking Gly57 and Asp58. The orientation of this peptide, the central unit in a reverse bend, is drastically altered as a consequence of reduction of the adjoining FMN. We hoped that refinement would allow us to reassign unambiguously the conformation of each oxidation state in this region, and a number of the computational approaches were chosen with this objective. For instance, removal of atoms in residues 56 to 59 from $F_{c}$ and $\alpha_{c}$ was deemed essential for fresh interpretation of the densities corresponding to this sequence. After refinement $\left(2\left|F_{\mathrm{o}}\right|\right.$ - $\left.\left|F_{c}\right|\right)$ "deletion" maps of uxidized and semiquinone flavodoxins are clearly distinguishable in this region, and possess the same features as originally observed in isomorphous replacement maps. Fitting of the final $\left(2\left|F_{\mathrm{o}}\right|-\left|F_{\mathrm{c}}\right|\right)$ maps by real space refinement provides a satisfactory interpretation of the semiquinone density; a difference map, with atoms of Gly57 and Asp58 included in the phases, is relatively clean (Fig. 6(b)). Some difficulty still remains in the interpretation of the $\left(2\left|F_{\mathrm{o}}\right|\right.$ $\left.-\left|F_{c}\right|\right)$ maps of oxidized flavodoxin. As in Figure $5(b), \mathrm{N}(57)$ is at the border of the density, and an $\left(\left|F_{o}\right|-\left|F_{c}\right|\right)$ synthesis displays significant density, particularly a positive peak near $\mathrm{C}_{a}(57)$. However, our reservations about the conformation assigned to oxidized flavodoxin do not affect the conclusion that a conformation change occurs at residues 57 and 58 .

Co-ordinate adjustments during refinement have led to some changes in our earlier assignment of possible flavin-protein hydrogen bonds (Burnett et al., 1974; Mayhew \& Ludwig, 1975). For example, initial co-ordinates suggested a hydrogen bond between $\mathrm{O4}^{\prime}$ and an amide $\mathrm{O}$ (or $\mathrm{N}$ ) of Asn 119. The distance between these atoms is now $3.9 \AA$ in oxidized flavodoxin and $4 \cdot 2 \AA$ in the semiquinone structure.

\section{(b) Special aspects of the structure of flavodoxin semiquinone}

Structure analyses of model isoalloxazine radicals have been hampered by their tendency to dismute to mixtures of the reduced and oxidized species, and the properties of flavin radicals have been deduced from spectroscopic data. In contrast, flavodoxins permit examination of the semiquinone species with minimal admixture of the other oxidation states.

The neutral or "blue" flavin radical is found in flavodoxins, even at high $\mathrm{pH}$. The electronic structure of the neutral species and the position of the proton (at $N(5)$ ) have been established by electron paramagnetic resonance spectroscopy, using model compounds (Müller et al., 1970,1971) (see Fig. 13). In those flavoproteins which stabilize the neutral radical the electron paramagnetic resonance spectrum is characteristically broadened, indicating protonation at $\mathrm{N}(5)$ (Palmer et al., 1971). Although the $\mathrm{p} K$ for dissociation of the $\mathrm{N}(5)$ proton is 8.55 in FMN semiquinone (Draper \& Ingraham, 1968), it has been estimated to be about 11.5 for flavodoxin from Azotobacter vinelandii (Edmondson \& Tollin, 1971). Spectroscopic measurements (Eaton et al., 1975 ) verify that $N(5)$ is protonated in our semiquinone crystals.

In flavodoxin from Clostridium $M P$, the increased $\mathrm{p} K$ can be ascribed primarily 


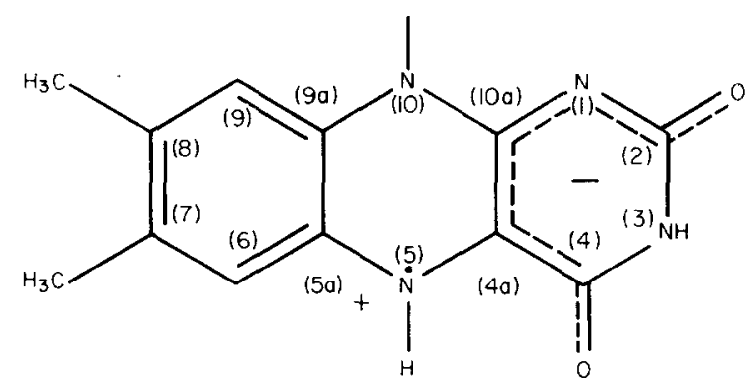

FIG. 13. The predominant electronic structure of neutral isoalloxazine semiquinone (Müller et al., 1970).

to the hydrogen bond between $\mathrm{NH}(5)$ and 057 . Negative charges on Asp58 $(6 \cdot 9 \AA$ away) and Glu59 (5.8 $\AA$ distant) may exert a secondary influence. The strength of the hydrogen bond may be estimated from the following model, which assumes a simple dissociation from the hydrogen-bonded species with no accompanying changes in the protein molecule. The formation of the hydrogen bond, equation (3), below, would be represented by the difference between the first two equilibria:

$$
\begin{aligned}
& \bullet \mathrm{FH} \rightleftharpoons \bullet^{-} \mathrm{F}^{-}+\mathrm{H}^{+}(\mathrm{p} K=8 \cdot 55) \\
& { }^{\bullet} \mathrm{FH} \ldots \mathrm{A} \rightleftharpoons \bullet^{-}+\mathrm{H}^{+}+\mathrm{A}(\mathrm{p} K=11 \cdot 5) \\
& \bullet \mathrm{FH}+\mathrm{A} \rightleftharpoons{ }^{\bullet} \mathrm{FH} \ldots \mathrm{A},
\end{aligned}
$$

where $\mathrm{A}$ is the hydrogen-bond acceptor. The difference in $\mathrm{p} K$ for reaction (1) and (2) can be converted to a free energy for formation of the hydrogen bond of $-4.0 \mathrm{kcal} / \mathrm{mol}$ at $25^{\circ} \mathrm{C}$.

The spectra of model compounds and of flavoproteins imply that the neutral isoalloxazine ring is planar. The most compelling evidence comes from the existence of low energy $\pi-\pi^{*}$ transitions in the 500 to $600 \mathrm{~nm}$ region (Beinert, 1956; Massey \& Palmer, 1966; Land \& Swallow, 1969). Like the related transitions in planar oxidized flavins (Song, 1969; Lhoste, 1971; Sun et al., 1972) these transitions are polarized along the long axis of the isoalloxazine nucleus (Eaton et al., 1975). The transition probabilities are approximately half those for oxidized flavins. Computations of spin density distributions in neutral flavin radicals have assumed trigonal geometry for $\mathrm{N}(5)$ and $\mathrm{N}(10)$ (Karreman, 1961 ; Song, 1969). Furthermore, ENDOR spectra have been interpreted as indicating that the semiquinone ring is planar in flavodoxin from A. vinelandii (Eriksson \& Ehrenberg, 1973).

The close correspondence of the solution and crystal spectra of flavodoxin semiquinone (Eaton et al., 1975) led us to expect that the electron density maps would reveal an essentially planar isoalloxazine ring. At $3.25 \AA$ resolution (Andersen et al., 1972) no deviation from planarity could be detected. The torsion angle about the $\mathbf{N}(10)-N(5)$ axis reported in this paper, $-2 \cdot 5^{\circ}$, is less than the angle found in some model "planar" oxidized flavins. Indeed, the values of Table 5 probably represent an upper limit for the magnitude of the bending, because they may be influenced by the presence in the crystal of some fully reduced molecules $\dagger$. Ring bending as large as

$\uparrow$ The larger bending angle for the ring in flavodoxin semiquinone, determined earlier (Mayhew \& Ludwig, 1975), is attributed to over-reduction. 
$-8 \cdot 6^{\circ}$ has been calculated for reduced flavodoxin from Clostridium MP (Ludwig et $a l ., 1976)$.

\section{(c) Electron transfer}

In electron transfer reactions, flavodoxin interchanges electrons with other flavoproteins, with $\mathrm{Fe} / \mathrm{S}$ centers, and with heme proteins. Because the oxidation-reduction potential for the semiquinone/reduced couple approximates that for ferredoxins, it is generally assumed that flavodoxins alternate between their two lower oxidation states in vivo (Mayhew et al., 1969). The reactions of flavodoxins with nitrogenase provide some experimental basis for this assumption (Yates, 1972).

Contact of the isoalloxazine ring with solvent or with electron donors is severely restricted by the surrounding protein atoms as can be seen in Figures 8 and 12. On the "protein side" of the flavin ring, residues 55, 56, 59 and 88 allow access only to $O(2)$ and the methyl groups at $\mathrm{C}(7)$ and $\mathrm{C}(8)$. Trp90, and the backbone atoms of residues 57, 58, 89 and 91 shield the pyrimidine and central pyrazine rings in the other directions. However, the methyl groups, $\mathrm{C}(6), \mathrm{C}(7)$ and $\mathrm{C}(8)$ are more than $4 \AA$ from any atom of Trp90 and can interact with other molecules approaching end on or alongside the indole ring of Trp90 (see Fig. 12). Access to the flavin ring is not substantially different in any of the three oxidation states, and is similarly restricted in $D$. vulgaris flavodoxin (Watenpaugh et al., 1972,1973a). "Direct" electron transfer at $\mathrm{N}(5)$ or $O(4)$, as exemplified in model flavin radical chelates (Hemmerich et al., 1965) could only be accomplished by considerable rearrangement of the protein structure. Hence the crystallographic results lead one to entertain alternative mechanisms in which electrons are transferred via the dimethylbenzene portion of FMN (Favaudon \& Lhoste, 1975).

\section{(d) Redox properties of flavodoxins: comparisons of the oxidation states}

Flavodoxins act as one-electron reagents and thermodynamic stabilization of the intermediate radical state is therefore a key property of these molecules. Preliminary studies of reduced flavodoxin have suggested explanations for the small $K_{\text {a }}$ of the fully reduced prosthetic group, and hence for the low potential of the couple flavodoxin $_{\mathrm{sq}} /$ flavodoxin $_{\text {reduced }}$ (Ludwig et al., 1976). In this paper we are primarily concorned with comparison of the oxidized and semiquinone structures.

The stability of the semiquinone, relative to the oxidized species, can be expressed as the difference in free energy of association of FMN and apoprotein, $\delta \Delta G$, for the oxidized and semiquinone states, and can be calculated from the shift in redox potential for the couple, $\mathrm{FMN}_{\mathrm{ox}} / \mathrm{FMN}_{\mathrm{sq}}$, which occurs upon combination with the protein. For flavodoxin from Clostridium $M P$ association with the FMN radical is favored by about $3 \cdot 4 \mathrm{kcal} / \mathrm{mol}$ over association with oxidized FMN (Mayhew, 197la). A complete accounting for this $\delta \Delta G$ would include differences in the conformational energy of the apoprotein in each of the holoprotein structures, differences in the number or strength of protein-flavin interactions, and any differential variations in the conformational energy of FMN in its free and bound forms.

Comparison of the structures of oxidized and semiquinone flavodoxins reveals several features which should substantially affect the relative conformational energies calculated for the two higher oxidation states of flavodoxin. Our discussion is confined to the flavin binding region. 
(i) Conformation changes involving the reverse bend at residues 56 to 59

In the semiquinone molecule, the reverse bend at residues 56 to 59 is related to the "standard" type I bend (Venkatachalam, 1968), but is so distorted that the $3_{10}$ hydrogen bond probably does not form. Similarly, the conformation proposed for oxidized flavodoxin is distorted from the classical type II bend, with consequent weakening of the 056-NH59 interaction. Calculations on the model type I and II structures show that the type $I I$ bend is less stable when a side-chain is present at the third position (corresponding to Asp58 in our case), largely on account of the nearly eclipsed arrangement of the second $\mathrm{C}-\mathrm{O}$ and third $\mathrm{C}_{a}-\mathrm{C}_{\beta}$ bonds (Venkatachalam, 1968; Chandrasekaran et al., 1973). Despite large departures from the model $\phi, \psi$ angles (Table 4), a near-gauche orientation of these $\mathrm{C}-\mathrm{O}$ and $\mathrm{C}_{\alpha}-\mathrm{C}_{\beta}$ bonds is maintained in the conformation proposed for oxidized flavodoxin (Fig. 5(b)). The distance between $\mathrm{O}(57)$ and the $\mathrm{AspC}_{\beta}$ is $2.56 \AA$. Hence the reverse bend at residues 56 to 59 in oxidized flavodoxin may be less stable than the one found in flavodoxin semiquinone.

\section{(ii) $F M N$-protein interactions}

The contacts between Trp90 and the flavin ring differ in oxidized and semiquinone flavodoxins. Changes in the electronic structure of the flavin, as electrons are added, are expected to alter its ability to complex aromatic groups (Massey \& Ghisla, 1974). Draper \& Ingraham (1970) have studied complexes of indoles with flavins and conclude that association is strongest for the semiquinone species. However, it is not obvious that the energy differences determined for models can be assigned to the flavodoxin structures. Further, Trp90 is particularly susceptible to the influence of intermolecular contacts because of its position in the molecule, and we cannot be certain that the co-ordinate changes seen in the crystal occur in solution.

Changes in other non-bonded contacts between FMN and the apoprotein may be important. One of the larger co-ordinate shifts involves the sulfur of Met56, which moves farther from the isoalloxazine ring in the semiquinone structure (Table 8 , Fig. 11). The relative strengths of some hydrogen bonds found in both oxidation states may be affected by changes in atomic positions. For example, 055 and $04^{\prime}$ shift by more than $0 \cdot 4 \AA$ (Table 8 ).

Isoalloxazine-protein hydrogen bonds undoubtedly affect the redox potentials of the protein bound flavin. The interactions at $\mathrm{N}(1), \mathrm{O}(2), \mathrm{N}(5)$ and possibly $\mathrm{O}(4)$ depend on the oxidation state as a result of changes in atomic co-ordinates and variations in the electronic structure of the isoalloxazine.

FMN atoms $\mathrm{N}(1)$ and $\mathrm{O}(2)$ have possible hydrogen-bonding partners in all three oxidation states of clostridial flavodoxin. However, the position of $\mathrm{NH} 91$, which hydrogen-bonds to $O(2)$, alters by more than $0.4 \AA$ when the oxidized molecule is reduced to the semiquinone. Difference maps (Ludwig et al., 1976) suggest that the geometry at $N(1)$ and $O(2)$ is very similar in semiquinone and reduced flavodoxins, but in the anionic reduced $\mathrm{FMNH}^{-}$, a negative charge is redistributed over $\mathrm{N}(1)$ and $\mathrm{O}(2)$. Hence the hydrogen bonds involving NH89 and NH91 may provide considerable stronger flavin-protein interactions in the reduced than in the oxidized or semiquinone states. In summary, the energy associated with the network of hydrogen bonds to the pyrimidine portion of the FMN is expected to vary with oxidation state. 
A hydrogen bond between $\mathrm{NH}(5)$ and 057 occurs in the semiquinone but not in the oxidized state. This interaction not only alters the $\mathrm{p} K$ of $\mathrm{NH}(5)$, but also stabilizes the semiquinone oxidation state. Even in the absence of a conformation change at residues 57 to 58 , this hydrogen bond could not occur in oxidized flavodoxin, because $\mathrm{N}(5)$ is not protonated in oxidized FMN. The only candidate for a hydrogen bond unique to oxidized flavodoxin would be $\mathrm{O}(4)-\mathrm{HN} 58$, but the present co-ordinates arc inconsistent with appreciable hydrogen bonding-interaction between these atoms.

In evaluating the contribution of the $057-\mathrm{HN}(5)$ hydrogen bond, a set of electrostatic interactions in the semiquinone structure, involving 057 and the flavin atoms $\mathrm{N}(5)$ and $\mathrm{O}(4)$, must be considered. Oxygen 57 is $2.80 \AA$ from $\mathrm{N}(5)$ and $3 \cdot 15 \AA$ from $\mathrm{O}(4)$. In energy calculations, charges of about -0.4 and +0.45 have been assigned to the $\mathrm{O}$ and $\mathrm{C}$ of backbone carbonyl groups (Momany et al., 1975). A formal positive charge resides on $\mathrm{HN}(5)$ in the predominant valence structure of the neutral isoalloxazine radical (Fig. 13); as a result the electrostatic contribution to the $057-\mathrm{HN}(5)$ interaction will be large, and the $057-\mathrm{HN}(5)$ hydrogen bond is expected to be very stable (Parthasarathy, 1977). On the other hand, the arrangement of the backbone carbonyl 57 and flavin $\mathrm{C}(4)-\mathrm{O}(4)$ dipoles (Figs 6, 8 and 11 ) should lead to significant electrostatic repulsion. We are not able to calculate either the hydrogen bond or repulsive energies precisely, as atomic charges have been computed by molecular orbital methods for oxidized (Song, 1968,1969), but not for semiquinone, isoalloxazines. In the oxidized flavin ring, $O(4)$ has a charge of $-0 \cdot 3$ to $-0 \cdot 4$, and $\mathrm{C}(4)$ a change of $+0 \cdot 35$. We surmise that in the structure of flavodoxin semiquinone the favorable 057-HN(5) interaction energy is larger than the repulsion between the two carbonyl dipoles. However, the $\mathrm{O}(4)-057$ repulsion may promote reorientation of the 57 to 58 peptide unit in oxidized flavodoxin.

The strong hydrogen bond to $\mathrm{HN}(5)$ provides a chemically logical device for preferential stabilization of the radical species. $\mathrm{N}(5)$ is a strong base in the isoalloxazine radical but not in the other oxidation states; the properties of this nitrogen prompted the prediction that hydrogen-bonding at $\mathrm{N}(5)$ would be found in those flavoproteins which form the half-reduced species in large yields (Müller et al., 1970,1971; Hemmerich \& Wessiak, 1976).

It will be interesting to determine if other flavodoxins similarly utilize the hydrogenbonding capacity of $\mathrm{N}(5)$ in the neutral semiquinone. The redox behavior of flavodoxin from $D$. vulgaris resembles that of the flavodoxin from Clostridium $M P$, with the oxidized/semiquinone potential becoming more positive than that for FMN and the semiquinone/reduced potential much more negative than for free FMN (Dubourdieu \& LeGall, 1970; Barman \& Tollin, 1972). Although the details of the flavin surroundings are quite different in flavodoxins from Clostridium $M \Gamma$ and $D$. vulgaris, Gly61 in $D$. vulgaris flavodoxin is roughly equivalent to Gly57 in our structure. After reduction of $D$. vulgaris flavodoxin to the semiquinone state, changes in the electron density are observed in the vicinity of residue 62 , whose amide group forms a hydrogen bond to the flavin $O(4)$ in the oxidized molecule. One interpretation of the changes near residue 62 reorients the peptide connecting Gly61 with Asp62 to form a $061-\mathrm{HN}(5)$ hydrogen bond in the semiquinone (Watenpaugh et al., 1976).

Throughout the families of proteins which participate in biological oxidations, the redox potentials of prosthetic groups are found to be affected by interaction with the apoproteins to which they complex. In flavodoxin from Clostridium $M P$, the 
redox potentials are modulated both by the protein microenvironment and by alterations in the tertiary structure of the protein. In the case of fully reduced flavodoxin, the potential may also be affected by constraints on the motion and conformation of bound FMNH- (1udwig et al., 1976). Comparison of the oxidized and semiquinone structures discloses a series of structural changes which must be considered in accounting for the net stabilization of the semiquinone over the oxidized species. The most important favorable contribution seems to arise from formation of the $057-\mathrm{HN}(5)$ hydrogen bond in flavodoxin semiquinone.

This work has been supported by a research grant from the Public Health Service (GM 16429), by a National Institutes of Health Career Development award (GM 6611) to one of us (M. L. L.), and by Training grants to the Department of Biological Chemistry (GM 00187) and the Biophysics Research Division (GM 1355). Some of the computations were supported by the Computing Center at the University of Michigan.

\section{REFERENCES}

Anderscn, R. D. (1972). Ph.D. thesis, University of Michigan.

Andersen, R. D., Apgar, P. A., Burnett, R. M., Darling, G. D., LeQuesne, M. E., Mayhew, S. G. \& Ludwig, M. L. (1972). Proc. Nat. Acad. Sci., U.S.A. 69, 3189-3191.

Anderson, L. (1975). J. Mol. Biol. 94, 33-49.

Barman, B. G. \& Tollin, G. (1972). Biochemistry, 11, 4760-4765.

Beinert, H. (1956). J. Amer. Chem. Soc. 78, 5323-5328.

Burnett, R. M. \& Nordman, C. E. (1974). J. Appl. Crystallogr. 7, 625-627.

Burnett, R. M., Darling, G. D., Kendall, D. S., LeQuesne, M. E., Mayhew, S. G., Smith, W. W. \& Ludwig, M. L. (1974). J. Biol. Chem. 249, 4383-4392.

Chandrasekaran, R., Lakshminarayanan, A. V., Pandya, U. V. \& Ramachandran, G. N. (1973). Biochim. Biophys. Acta, 303, 14-27.

Cohen, G. H., Matthews, B. W. \& Davies, D. R. (1970). Acta Crystallogr. sect. B, 26, $1062-1069$.

Cox, E. G. \& Cruickshank, D. W. J. (1948). Acta Crystallogr. 1, 92-93.

Cox, J. M. (1967). J. Mol. Biol. 28, 151-155.

Darling, G. D. (1975). Ph.D. thesis, University of Michigan.

Diamond, R. (1966). Acta Crystallogr. 21, 253-266.

Diamond, R. (1971). Acta Crystallogr. sect. A, 27, 436452.

Diamond, R. (1974). J. Mol. Biol. 82, 371-391.

Dickerson, R. E., Weinzierl, J. E. \& Palmer, R. A. (1968). Acta Crystallogr. sect. B, 24, $997-1003$.

Draper, R. D. \& Ingraham, L. L. (1968). Arch. Biochem. Biophys. 125, 802-808.

Draper, R. D. \& Ingraham, L. L. (1970). Arch. Biochem. Biophys. 139, 265-268.

Dubourdieu, M. \& LeGall, J. (1970). Biochem. Biophys. Res. Commun. 38, 965-972.

Eaton, W. A., Hofrichter, J., Makinen, M. W., Andersen, R. D. \& Ludwig, M. L. (1975). Biochemistry, 14, 2146-2151.

Edmondson, D. E. \& Tollin, G. (1971). Biochemistry, 10, 133-145.

Eriksson, L. E. G. \& Ehrenberg, A. (1973). Biochim. Biophys. Acta, 295, 57-66.

Favaudon, V. \& Lhoste, J.-M. (1975). Biochemistry, 14, 4731-4738.

Freer, S. T., Alden, R. A., Carter, C. W., Jr \& Kraut, J. (1975). J. Biol. Chem. 250, 46-54.

Hemmerich, P. \& Wessiak, A. (1976). In Flavins and Flavoproteins (Singer, T. P., ed.), pp. 9-22, Elsevier, Amsterdam.

Hemmerich, P., Müllor, F. \& Ehronberg, A. (1965). In Oxidases and Rolated Redox Systems (King, T. E., Mason, H. S. \& Morrison, M., eds), vol. 1, pp. 157-178, Wiley, New York.

Henderson, R. (1970). J. Mol. Biol. 54, 341-354.

Hermans, J., Jr \& McQueen, J. E., Jr (1974). Acta Crystallogr. sect. A, 30, 730-739.

Huber. R., Kukla, D., Bode, W., Schwager, P., Bartels, K., Deisenhofer, J. \& Steigemann, W. (1974). J. Mol. Biol. 89, 73-101. 
James, T. L., Ludwig, M. L. \& Cohn, M. (1973). Proc. Nat. Acad. Sci., U.S.A. 70, 32923295.

Karreman, G. (1961). Bull. Math. Biophys. 23, 55-68.

Kierkegaard, P., Norrestam, R., Werner, P.-E., Csöregh, I., von Glehn, M., Karlsson, R., Leijonmarck, M., Rönnquist, O., Stensland, B., Tillberg, O. \& Torbjornsson, L. (1971). In Flavins and Flavoproteins (Kamin. H., ed.), pp. 1-21, University Park Press, Baltimore.

Kim, H. S., Jeffrey, G. A. \& Rosenstein, R. D. (1969). Acta Crystallogr. sect. B, 25, 2223-2230 .

Knight, E., Jr \& Hardy, R. W. F. (1966). J. Biol. Chem. 241, 2752 2756.

Kraut, J., High, D. F. \& Sieker, L. C. (1964). Proc. Nat. Acad. Sci., U..S.A. 51, 839 845.

Land, E. J. \& Swallow, A. J. (1969). Biochemistry, 8, $2117-2125$.

Levitt, M. (1974). J. Mol. Biol. 82, 393-420.

Lhoste, J. M. (1971). In Proc. First Europ. Biophys. Congr. (Broda, E., Locker, A. \& Springer-Lederre, H., eds), vol. 4, pp. 221, Verlag der Wiener Medizinischen Akademie, Vienna.

Lipscomb, W. N., Coppola, J. C., Hartsuck, J. A., Ludwig, M. L., Muirhead, H., Searl, J. \& Steitz, T. A. (1966). J. Mol. Biol. 19, 423-441.

Ludwig, M. L., Andersen, R. D., Mayhew, S. G. \& Massey, V. (1969). J. Biol. Chem. 244, $6047-6048$.

Ludwig, M. L., Andersen, R. D., Apgar, P. A. \& LeQuesne, M. E. (1971). In Flavins and Flavoproteins (Kamin, H., ed.), pp. 171-184, University Park Press, Baltimore.

Ludwig, M. L., Burnett, R. M., Darling, G. D., Jordan, S. R., Kendall, D. S. \& Smith, W. W. (1975). In Structure and Conformation of Nucleic Acids and Protein-Nucleic Acid Interactions (Sundaralingam, M. \& Rao, S. T., eds), pp. 407-429, University Park Press, Baltimore.

Ludwig, M. L., Burnett, R. M., Darling, G. D., Jordan, S. R., Kendall, D. S. \& Smith, W. W. (1976). In Flavins and Flavoproteins (Singer, T. P., ed.), pp. 393-404, Elsevier, Amsterdam.

Massey, V. \& Ghisla, S. (1974). Ann. N.Y. Acad. Sci. 227, 446-465.

Massey, V. \& Palmer, G. (1966). Biochemistry, 5, 3181-3189.

Matthews, B. W. (1970). In Crystallographic Computing (Ahmed, F. R., ed.), pp. 146-150, Munksgaard, Copenhagen.

Mayhew, S. G. (1971a). Biochim. Biophys. Acta, 235, 276-288.

Mayhew, S. G. (1971b). Biochim. Biophys. Acta, 235, 289-302.

Mayhew, S. G. \& Ludwig, M. L. (1975). In The Enzymes (Boyer, P. D., ed.), 3rd edit., vol. 12, pp. 57-118, Academic Press, New York.

Mayhew, S. G., Foust, G. P. \& Massey, V. (1969). J. Biol. Chem. 244, 803-810.

Moews, P. C. \& Kretsinger, R. H. (1975). J. Mol. Biol. 91, 201-228.

Momany, F. A., McGuire, R. F., Burgess, A. W. \& Scheraga, H. A. (1975). J. Phys. Chem. 79, 2361-2381.

Muirhead, H., Cox, J. M., Mazzarella, L. \& Perutz, M. F. (1967). J. Mol. Biol. 28, 117-156.

Müller, F., Hemmerich, P., Ehrenberg, A., Palmer, G. \& Massey, V. (1970). Eur. J. Biochem. 14, 185-196.

Müller, F., Hemmerich, P. \& Ehrenberg, A. (1971). In Flavins and Flavoproteins (Kamin, H., ed.), pp. 107-122, University Park Press, Baltimore.

Norrestam, R. \& von Glehn, M. (1972). Acta Crystallogr. sect. B, 28, 434-446.

North, A. C. T. (1965). Acta Crystallogr. 18, 212-216.

North, A. C. T., Phillips, D. C. \& Mathews, F. S. (1968). Acta Crystallogr. sect. A, 24, 351-359.

Palmer, G., Müller, F. \& Massey, V. (1971). In Flavins and Flavoproteins (Kamin, H., ed.), pp. 123-140, University Park Press, Baltimore.

Parthasarathy, R. (1977). Amer. Crystallogr. Assn Meeting (Feb., 1977), Abstracts, p. 38.

Rae, A. D. (1965). Acta Crystallogr. 19, 683-684.

Rao, S. T. \& Rossmann, M. G. (1973). J. Mol. Biol. 76, 241-256.

Richards, F. M. (1968). J. Mol. Biol. 37, 225-230.

Rossmann, M. G. \& Argos, P. (1975). J. Biol. Chem. 250, 7525-7532. 
Scheraga, H. A. (1968). Advan. Phys. Org. Chem. 6, 103-183.

Sinillie, R. M. (1965). Biochem. Biophys. Res. Commun. 20, 621-629.

Smith, W. W. (1977). Ph.D. thesis, University of Michigan.

Song, P.-S. (1968). J. Phys. Chem. 72, 536-541.

Song, P.-S. (1969). Ann. N.Y. Acad. Sci. 158, 410-423.

Sun, M., Moore, T. A. \& Song, P.-S. (1972). J. Amer. Chem. Soc. 94, 1730-1740.

Sundaralingam, M. \& Jensen, L. H. (1965). J. Mol. Biol. 13, 930 943.

Tanaka, M., Hani1, M., Yasunobu, K. T. \& Mayhew S. (1. (1974), I. Biol Chem. 249, 4393- 4396 .

Ten Eyck, L. F. (1973). Acta Crystallogr. sect. A, 29, 183191.

Tonaka, N.. Ashida, T., Sasada. Y. \& Kakudo, M. (1967). Chem. Soc. Japan. Bull. 40, 1739 .

van Lin, B. \& Bothe, H. (1972). Arch. Mikrobiol. 82, 155-172.

Venkatachalam, C. M. (1968). Biopolymers, 6, 1425-1436.

Wade, T. D. \& Fritchie, C. J., Jr (1973). J. Biol. Chem. 248, 2337-2343.

Wang, M. \& Fritchie, C. J., Jr (1973). Acta Crystallogr. sect. B, 29, 2040-2045.

Watenpaugh, K. D., Sieker, L. C., Jensen, L. H., LeGall, J. \& Dubourdieu, M. (1972). Proc. Nat. Acad. Sci., U.S.A. 69, 3185 3188.

Watenpaugh, K. D., Sieker, L. C.\& Jensen, 1. H. (1973a). Proc. Nat. Acad. Sci., U.S.A. 70. 38573860 .

Watenpaugh, K. D., Sieker, L. C., Herriott, J. R. \& Jensen, L. H. (1:73b). Acta Crystallogr. sect. $B, 29,943-956$.

Watenpaugh, K. D., Sieker, L. C. \& Jensen, L. H. (1976). In Flavins and Flavoproteins (Singer, T. P.. ed.), pp. 405 410, Elsevier, Amsterdam.

Watson, D. G. \& Kennard, O. (1973). Acta Crystallogr. sect. B, 29, 2358-2364.

Werner, P.-E. \& Ronnquist, O. (1970). Acta Chem. Scand. 24, 997-1009.

White, J. L., Hackert, M. L., Buehner, M., Adams, J., Ford, G. C., Lentz, P. J., Jr, Smiley, I. E., Steindel, S. J. \& Rossmann, M. G. (1976). J. Mol. Biol. 102, 759-779.

Wyckoff, H. W., Doseher, M., Tsernoglou, D., Inagami, T., Johnson, L. N., Hardman, K. D., Allewell, N. M., Kelly, D. M. \& Richards, l'. M. (1967). J. Mol. Biol. 27, 563578.

Wyekoff, H. W., Tsernoglot, D., Hanson, A. W., Knox, J. R.. Lee, B. \& Richards, F. M. (1970). J. Biol. Chem. 245, 305-328.

Yates, M. G. (1972). FEBS Letters, 27, 63-67. 